This item was submitted to Loughborough's Research Repository by the author.

Items in Figshare are protected by copyright, with all rights reserved, unless otherwise indicated.

\title{
Analysis of vehicle rollover dynamics using a high-fidelity model
}

\section{PLEASE CITE THE PUBLISHED VERSION}

http://dx.doi.org/10.1080/00423114.2013.863362

\section{PUBLISHER}

(C) Taylor \& Francis

VERSION

SMUR (Submitted Manuscript Under Review)

LICENCE

CC BY-NC-ND 4.0

\section{REPOSITORY RECORD}

Czechowicz, Maciej P., and Georgios Mavros. 2014. "Analysis of Vehicle Rollover Dynamics Using a Highfidelity Model”. Loughborough University. https://hdl.handle.net/2134/14740. 
This item was submitted to Loughborough's Institutional Repository (https://dspace.lboro.ac.uk/) by the author and is made available under the following Creative Commons Licence conditions.

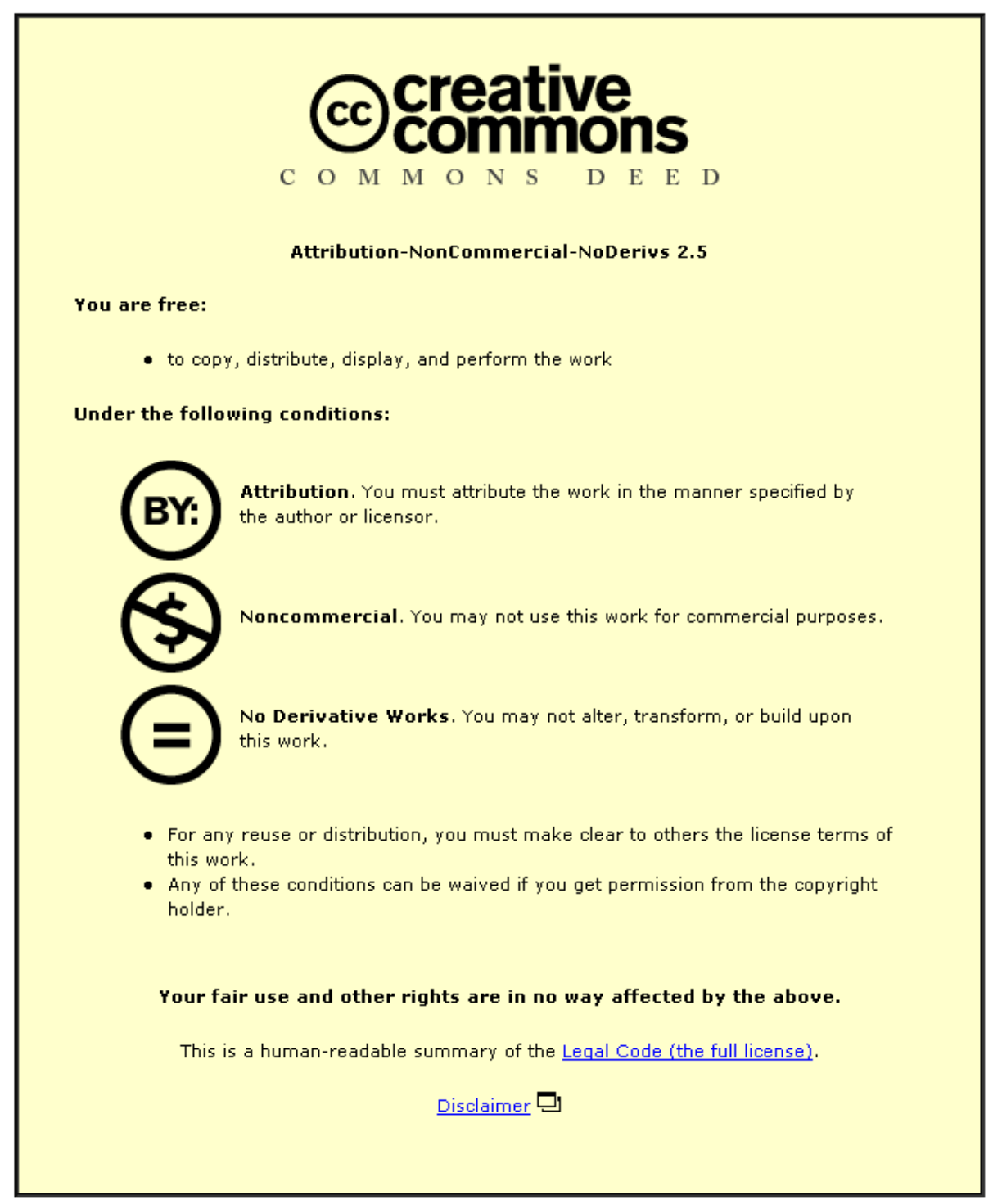

For the full text of this licence, please go to: http://creativecommons.org/licenses/by-nc-nd/2.5/ 


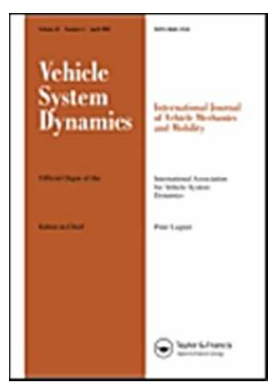

\section{Analysis of Vehicle Rollover Dynamics Using a High Fidelity Model}

\begin{tabular}{|r|l|}
\hline Journal: & Vehicle System Dynamics \\
\hline Manuscript ID: & NVSD-2013-0087 \\
\hline Manuscript Type: & Original Paper \\
\hline Date Submitted by the Author: & $09-$ Apr-2013 \\
\hline Complete List of Authors: & $\begin{array}{l}\text { Czechowicz, Maciej; Loughborough University, Aeronautical and } \\
\text { Automotive Engineering } \\
\text { Mavros, George; Loughborough University, Aero/Auto Engineering }\end{array}$ \\
\hline Keywords: & $\begin{array}{l}\text { Rollover, Stability analysis, Design of experiment, Multibody Systems < } \\
\text { Methods, Tyre }\end{array}$ \\
\hline
\end{tabular}

SCHOLARONE $^{\text {IM }}$

Manuscripts 


\title{
Analysis of Vehicle Rollover Dynamics Using a High Fidelity Model
}

\author{
Maciej Pawel Czechowicz, George Mavros
}

Aeronautical and Automotive Engineering Department, Loughborough University, Leicestershire, UK

Maciej Pawel Czechowicz, email: m.p.czechowicz@lboro.ac.uk

Aeronautical and Automotive Engineering

Stewart Miller Building

Loughborough University

Loughborough

Leicestershire LE11 3TU

This manuscript contains 6980 words excluding cover page, tables, references and appendix. 


\title{
Analysis of Vehicle Rollover Dynamics Using a High Fidelity Model
}

\begin{abstract}
Recent data shows that $35 \%$ of fatal crashes in SUVs included vehicle rollover. At the same time experimental testing to improve safety is expensive and dangerous. Therefore multi-body simulation is used in this research to improve understanding of rollover dynamics. The majority of previous work uses low fidelity models. Here a complex and highly nonlinear multibody model with 165 degrees of freedom is correlated to vehicle kinematic and compliance measurements. The Magic Formula tyre model is employed. Design of experiment methodology is used to identify tyre properties affecting vehicle rollover. A novel, statistical approach is used to link suspension kinematic and compliance characteristics with rollover propensity. Research so far reveals that the tyre properties that have the greatest influence on vehicle rollover are friction coefficient, friction variation with load, camber stiffness, and tyre vertical stiffness. Key kinematic and compliance characteristics affecting rollover propensity are front and rear suspension rate, front roll stiffness, front camber gain, front and rear camber compliance and rear jacking force.
\end{abstract}

Keywords: vehicle rollover, stability, design of experiment, multi-body simulation, tyre

\section{Introduction}

Although vehicle rollover is not a common type of accident, it is one of the most dangerous ones. National Highway Traffic Safety Administration (NHTSA) data [1] shows that $35.4 \%$ of recorded fatal crashes in SUVs included vehicle rollover. The effect of roll-over on an SUV vehicle tends to be more severe than for other types of passenger vehicles [2]. Due to the popularity of SUVs, their number on the roads is rising. Therefore, a thorough understanding of factors affecting the rollover resistance of SUVs is needed. As experimental testing to improve safety is expensive and dangerous, multi-body simulation is used in this work to improve understanding of 
rollover dynamics.

The majority of previous research work has been based on low fidelity models [3 - 7]. However, vehicle rollover is a highly non-linear event due to the large angles seen in vehicle body motion, extreme suspension travel, tyre non-linearities and large forces acting on the wheel, resulting in suspension spring-aids, rebound stops and bushings operating in the non-linear region. Lozia [7] compared the rollover threshold acceleration obtained from models with different levels of detail ranging from simple static equilibrium of a single body to a $14 \mathrm{DoF}$ model with step input steering wheel excitation. He concluded that the more sophisticated the model, the lower the rollover threshold, with the differences in the results reaching up to $38 \%$. The results presented by Shim et al. $[8,9]$ indicate that when compared to a complex multi-body model, the simple 14DoF model lacked some accuracy at extreme roll angles and after wheel liftoff because it didn't account for the changes in the suspension geometries and therefore the changes in roll centre height. Hac [10] suggests that reducing the roll centre heights and suspension nonlinearities, such as nonlinear springs, reduced jacking forces during cornering. Hac [11] also found that as the jacking forces tend to increase the vehicle's CoG during hard cornering, they also increase the tendency to rollover. Cole [12] noted that compliance in the suspension reduces the rollover threshold by increasing the lateral shift of the centre of mass towards the outer wheels. Hussain et al. [13] identified that rollover resistance can be improved by roll steer effects. Moreover suspension compliance effects such as compliance steer can also play a significant role as they affect understeer gradients. Taking into account the above findings, one can conclude that a high fidelity, nonlinear model is necessary to accurately simulate vehicle rollover. The work presented in the following sections investigates vehicle rollover using such a high fidelity model in conjunction with a DoE approach and statistical methods, 
aiming to systematically identify the sensitivity of rollover to various tyre and suspension related parameters. In this process, various rollover metrics are examined in conjunction with stability considerations and an appropriate rollover metric is devised.

When developing the dynamic properties of a vehicle, the suspension kinematic and compliance characteristics are investigated very thoroughly. Based on these characteristics, experienced development engineers are able to draw conclusions about the dynamics of a vehicle's steering and handling. The same could be done for vehicle rollover properties; however, current knowledge is somewhat limited, as the link between $\mathrm{K} \& \mathrm{C}$ characteristics and rollover are not routinely established by testing, due to the danger involved. Therefore, establishing a link between $\mathrm{K} \& \mathrm{C}$ suspension properties and vehicle rollover resistance is beneficial, as it will hopefully allow engineers to estimate how changes made to $\mathrm{K} \& \mathrm{C}$ suspension properties influence rollover resistance.

\section{Modelling}

In order to generate a high fidelity vehicle model able to capture complex, elastokinematic suspension characteristics, a multi-body simulation approach is often necessary. There exist a number of commercial MBS tools, which employ different approaches for the formulation of the equations of motion. Lagrange equations with holonomic constraints are routinely used [14]. This approach results in 6 DoF per rigid body with the associated ODEs for the corresponding states, whereas constraint reactions are represented by Lagrange multipliers. The constraints offer a number of algebraic equations which, together with the differential equations provide a differential/algebraic system to be solved iteratively for the DoFs and reaction forces. Whereas the process is robust, it is also computationally inefficient, as all bodies maintain their six DoFs in space, irrespective of the existence of constraints. In the 
context of carrying out a DoE study, a more efficient approach is beneficial. For this reason, a Newton-Euler approach is preferred, in conjunction with a relative kinematics formulation for the inclusion of the effects of constraints. The basic Newton-Euler equations describing the dynamics of a rigid body subjected to loads referenced at its centre of mass are presented below in matrix notation [15]:

$$
\left[\begin{array}{cc}
m & 0 \\
0 & \mathbf{I}
\end{array}\right] \cdot\left[\begin{array}{c}
\dot{\mathbf{v}}^{b} \\
\dot{\boldsymbol{\omega}}^{b}
\end{array}\right]+\left[\begin{array}{c}
\boldsymbol{\omega}^{b} \times m \boldsymbol{\omega}^{b} \\
\dot{\boldsymbol{\omega}}^{b} \times \mathbf{I} \boldsymbol{\omega}^{b}
\end{array}\right]=\mathbf{F}^{b},
$$

where $m$ - mass, $\mathbf{I}$ - inertia tensor, $\boldsymbol{v}^{b}$ - translational velocity in body coordinate frame, $\boldsymbol{\omega}^{b}$ - angular velocity in body coordinate frame, $\mathbf{F}^{b}$ - external forces and torques applied at centre of mass.

The number of $1^{\text {st }}$ order ODEs necessary to describe the motion of a system without any kinematic constraints is equal to:

$$
n_{O D E}=2 \cdot n_{D o F}=2 \cdot 6 \cdot k
$$

where $n_{D o F}$ - total number of degrees of freedom, $k$-number of bodies in the system

The key challenge in formulating equations of motion is the consideration of joints which constrain the relative motion of bodies [16]. The use of relative kinematics to describe the equations of motion, allows inclusion of constraints in the ODEs. Such an open loop kinematic system results in a reduced number of ODEs. All additional, closed loop constraints can then be included using algebraic equations. The total number of equations becomes:

$$
n_{O D E}=2 \cdot n_{D o F}=2 \cdot \sum_{i=1}^{k} n_{i}
$$

where $n_{D o F}$ - total number of degrees of freedom, $n_{i}$ - number of degrees of freedom 
for body $i$ in relative kinematics formulation.

Such a formulation is handled efficiently by SIMPACK which has in recent years become an industry standard in the field of multi-body simulation and is used by leading automotive companies. The details of formulation and solution method adopted by SIMPACK are described in [17].

The vehicle model set up for this research contains 165 degrees of freedom. Most of the suspension members have 6 degrees of freedom in order to accurately replicate suspension compliances. In addition, 2 rotational degrees of freedom are given to each hub, to account for the conical stiffness of the wheel bearing.

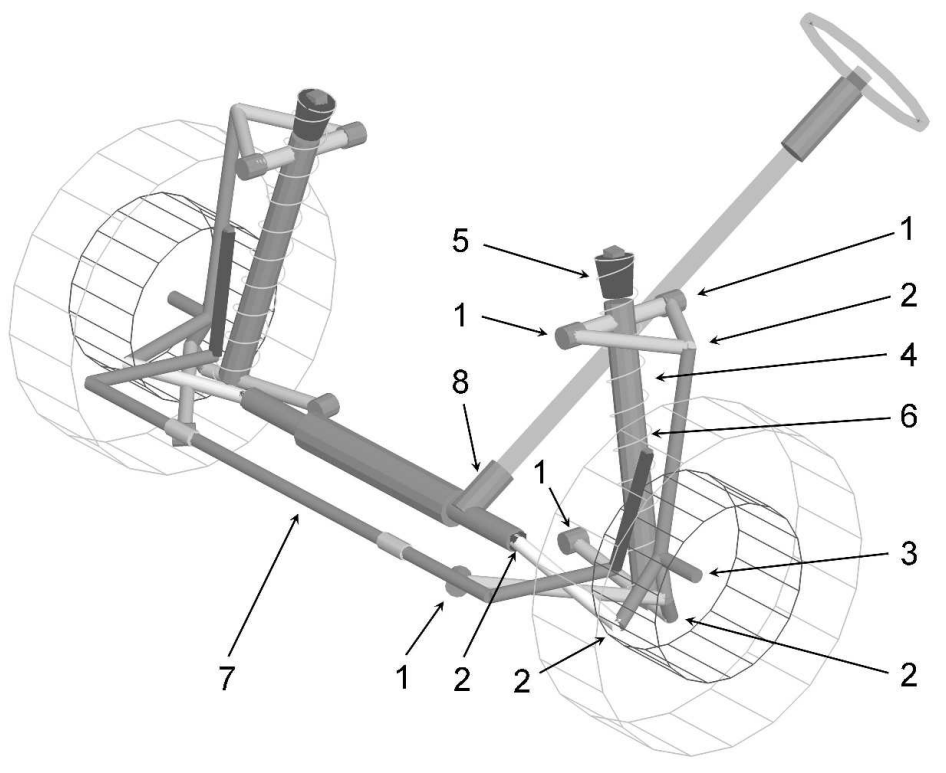

Figure 1. Source of suspension compliances in front axle model; 1 - bush, 2 - ball joint, 3 - hub compliance, 4 - spring, 5 - spring aid, 6 - rebound spring, 7 - anti-roll bar, 8 torsion bar. 


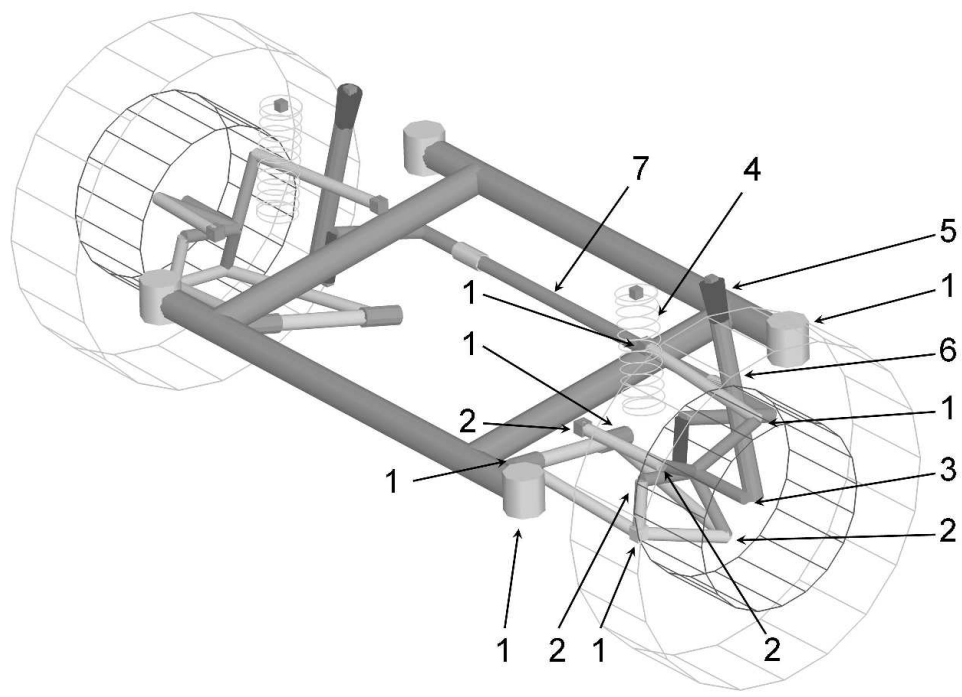

Figure 2. Source of suspension compliances in rear axle model; 1 - bush, 2 - ball joint, 3 - hub compliance, 4 - spring, 5 - spring aid, 6 - rebound spring, 7 - anti-roll bar.

The number of degrees of freedom for model subsystems is given in Table 1, while the main sources of compliance are shown in Figure 1 and Figure 2. Importantly, the model contains nonlinear elements for spring aids, rebound springs and dampers. The vehicle uses TNO's Magic Formula tyre model version 6.1. [18]. This model contains 15 internal states used to predict the dynamics of the tyre including relaxation lengths, to capture low bandwidth transient tyre response. The aim behind creating such a complex vehicle model is to replicate real vehicle behaviour in as much detail as possible and then treat that model as the subject of experiments.

\begin{tabular}{r|c} 
Subsystem & No. Degrees of Freedom \\
\hline Vehicle body & 6 \\
Front axle suspension & 78 \\
Rear axle suspension & 76 \\
Steering system & 1
\end{tabular}




\begin{tabular}{r|c} 
Wheels & 4 \\
\hline Total & 165
\end{tabular}

Table 1. Degrees of freedom in each subsystem.

\subsection{Model correlation}

Model parameterisation was based on two main sources of parameters. Some of the parameters involved direct measurement, or prior knowledge. Other parameters were derived from the correlation of a $\mathrm{K} \& \mathrm{C}$ test performed on the real vehicle. The vehicle model has been correlated to kinematic and compliance measurements of a real vehicle for the following tests:

- Test 1 (kinematics) - vehicle motion in pure vertical direction

- Test 2 (lateral compliance - opposite direction). Lateral forces applied at the contact patch, acting in the opposite direction at left and right-hand sides

- Test 3 (lateral compliance - same direction). Lateral forces applied at the contact patch, acting in the same direction for all wheels

- Test 4 (roll test). Vehicle roll motion

For all the above tests, the measured signals include contact patch forces, position and orientation of the wheel centre and position of wheel pad with respect to the body.

For correlation purposes a kinematic and compliance test rig was set up in SIMPACK, illustrated in Figure 3. The vehicle body and wheel pads were driven during the simulation by the signals acquired from physical measurements. Measurement signals were exported from the model and compared to the corresponding data from the physical test. The discrepancies between the model and physical results were corrected by methodically adjusting suspension parameters. The process consisted of the following comparisons between data from the model and the physical test: 
2

3

4

5

6

7

8

9

10

11

12

13

14

15

16

17

18

19

20

21

22

23

24

25

26

27

28

29

30

31

32

33

34

35

36

37

38

39

40

41

42

43

44

45

46

47

48

49

50

51

52

53

54

55

56

57

58

59

60

- compare results from test 1 and if necessary make small changes to the suspension geometry as well as spring, spring aid and rebound stop characteristics

- compare results from test 2 and adjust suspension bush compliances

- compare results from test 3 and adjust steering system compliance and rear subframe compliances

- compare results from test 4 and adjust anti-roll bar stiffnesses

To achieve good correlation several cycles were required. Examples of the resulting model correlation are show in Figures 4-15. For the purpose of concealing sensitive information the figures present normalised data.

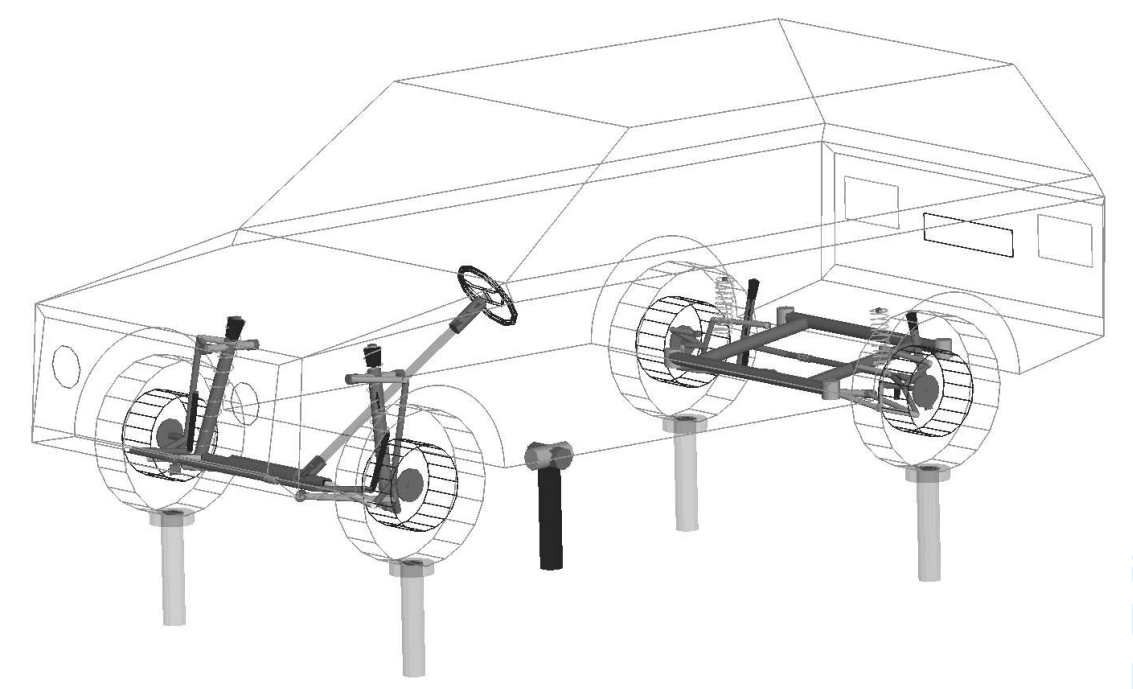

Figure 3. Vehicle model on kinematic and compliance test rig in SIMPACK. 


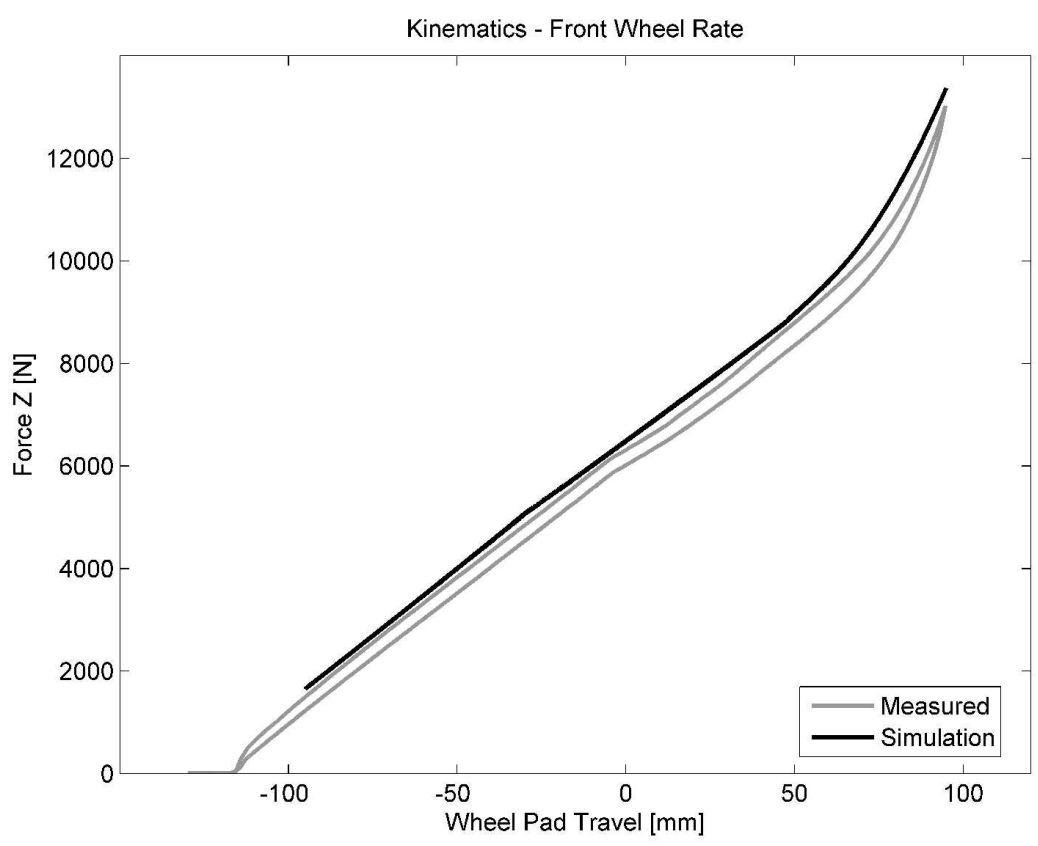

Figure 4. Example of model correlation - front wheel rate.

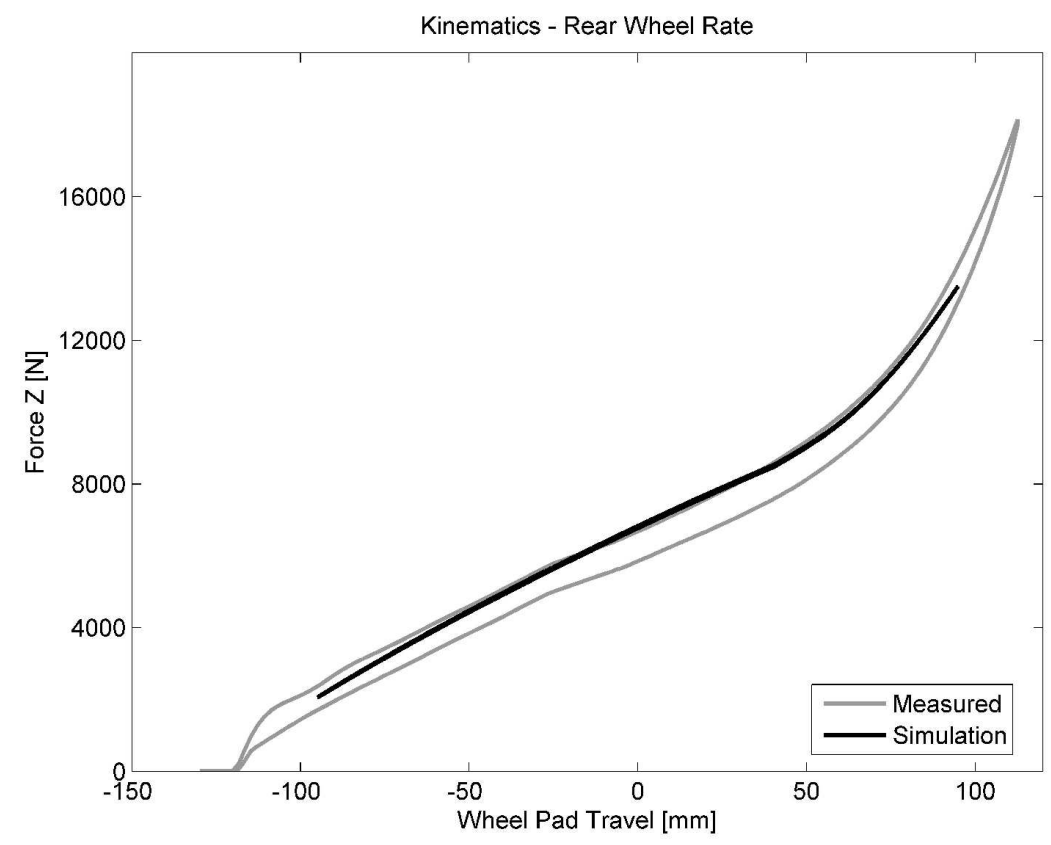

Figure 5. Example of model correlation - rear wheel rate. 
2

3

4

5

6

7

8

9

10

11

12

13

14

15

16

17

18

19

20

21

22

23

24

25

26

27

28

29

30

31

32

33

34

35

36

37

38

39

40

41

42

43

44

45

46

47

48

49

50

51

52

53

54

55

56

57

58

59

60

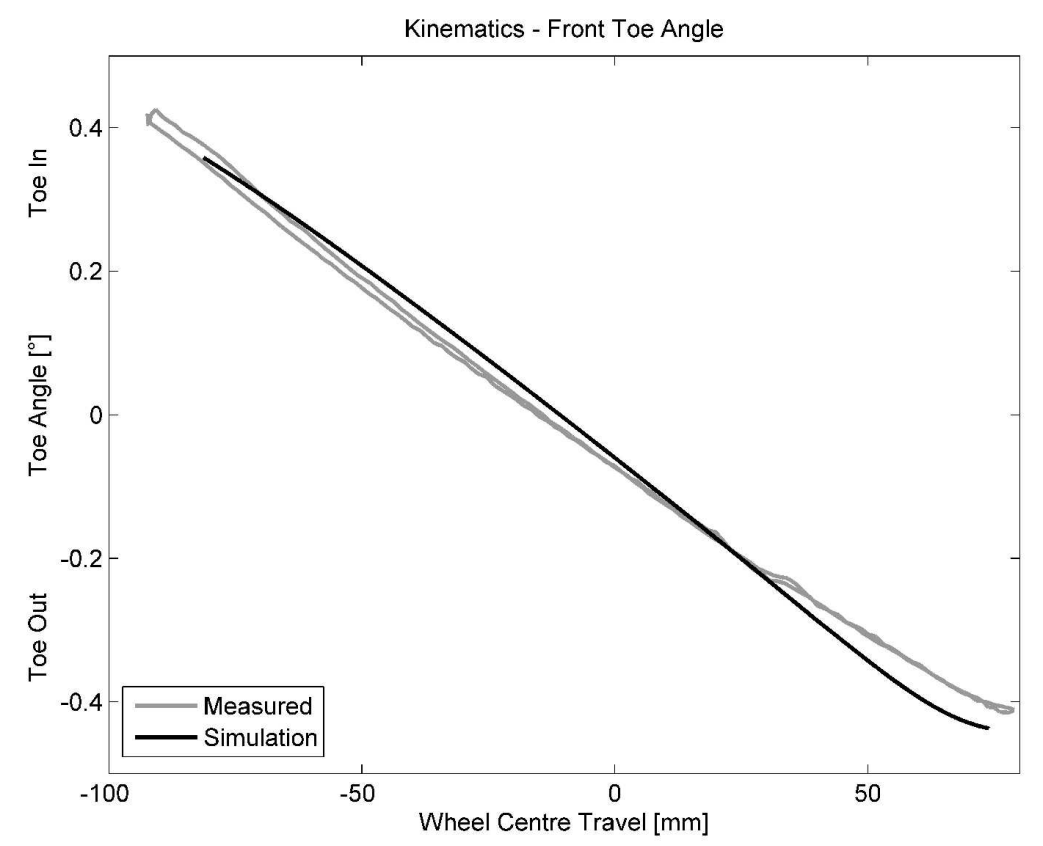

Figure 6. Example of model correlation - front toe kinematics.

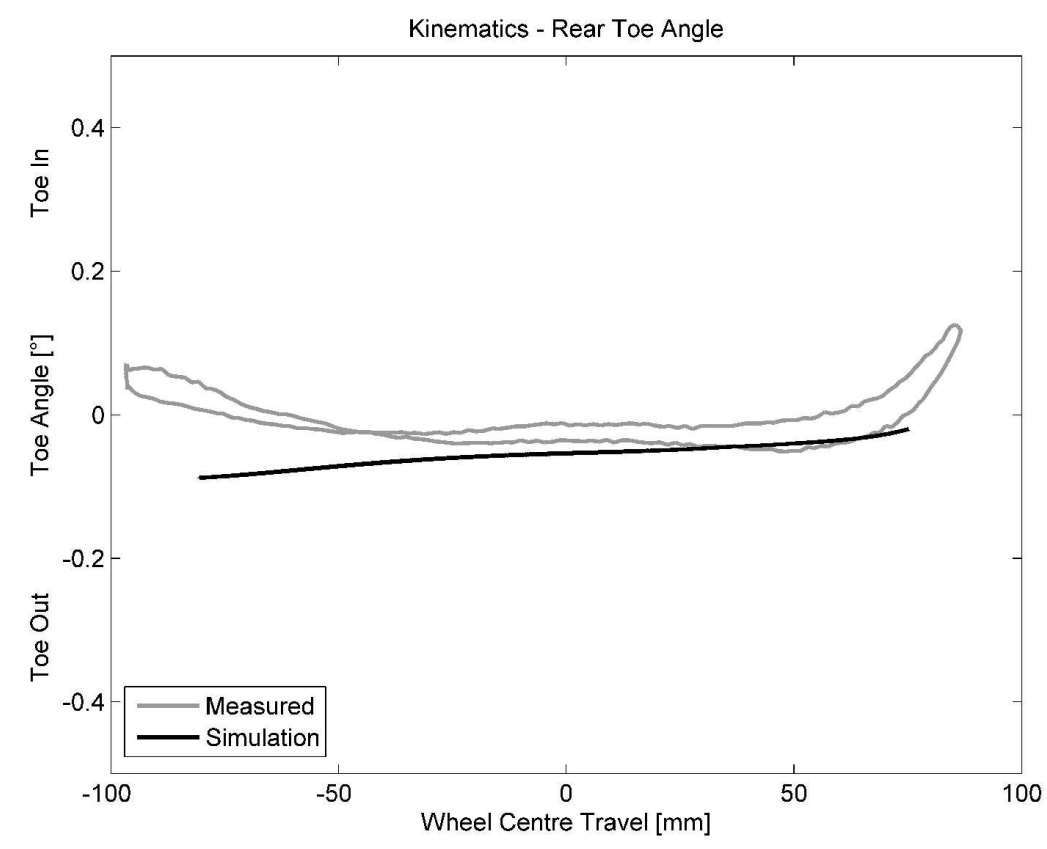

Figure 7. Example of model correlation - rear toe kinematics. 


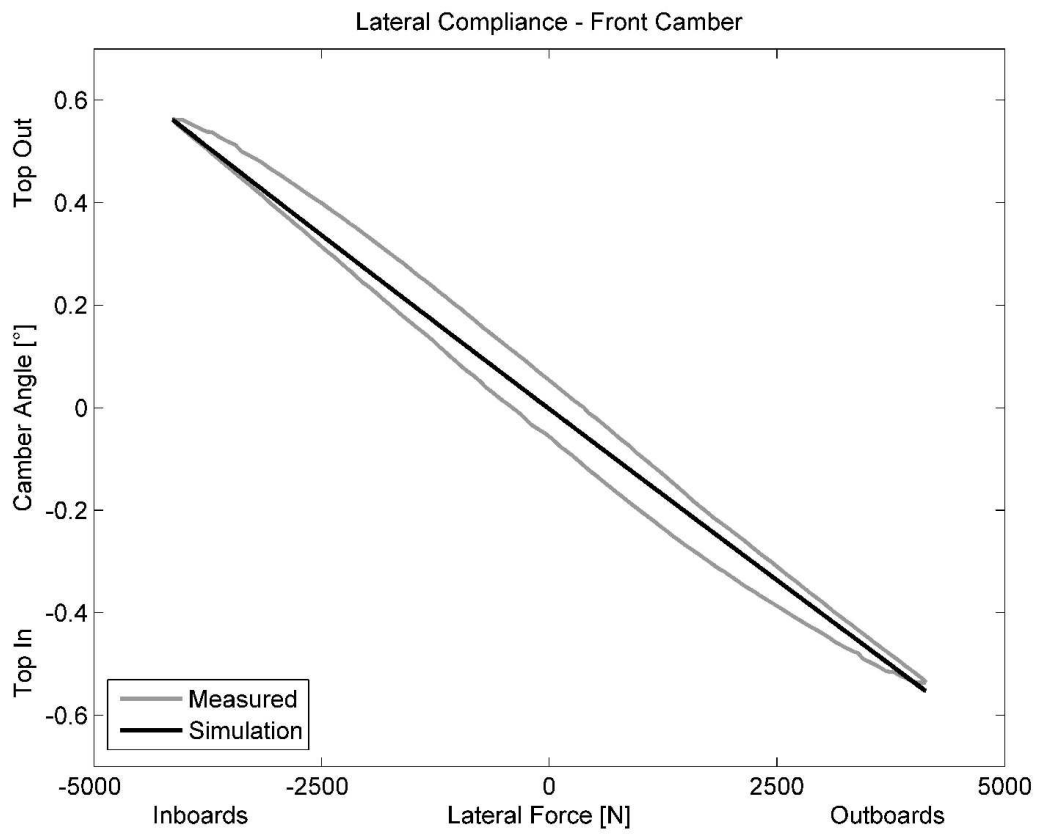

Figure 8. Example of model correlation - front camber compliance.

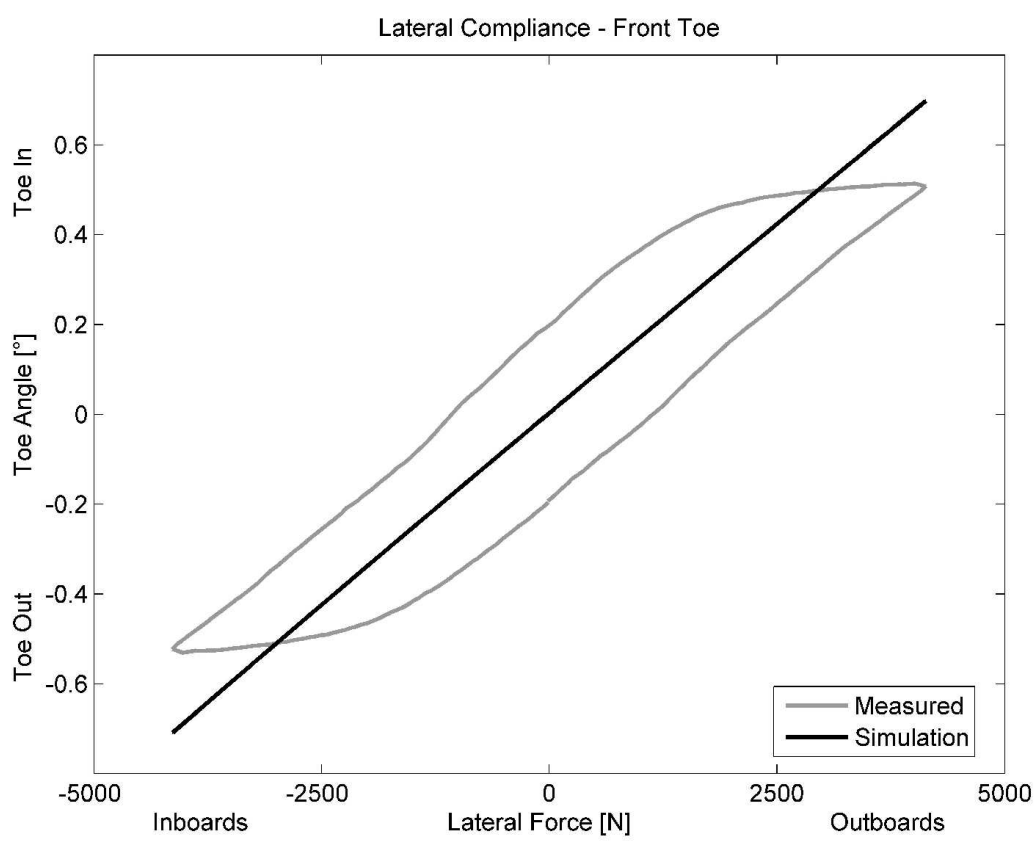

Figure 9. Example of model correlation - front toe compliance. 


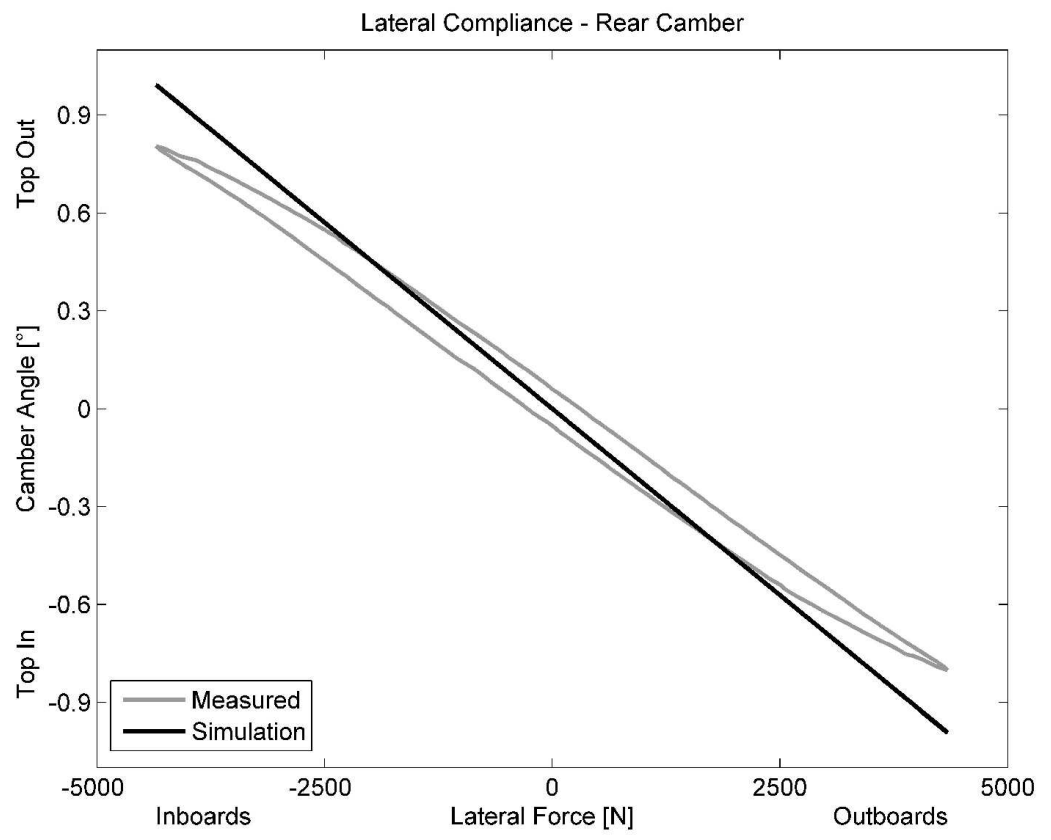

Figure 10. Example of model correlation - rear camber compliance.

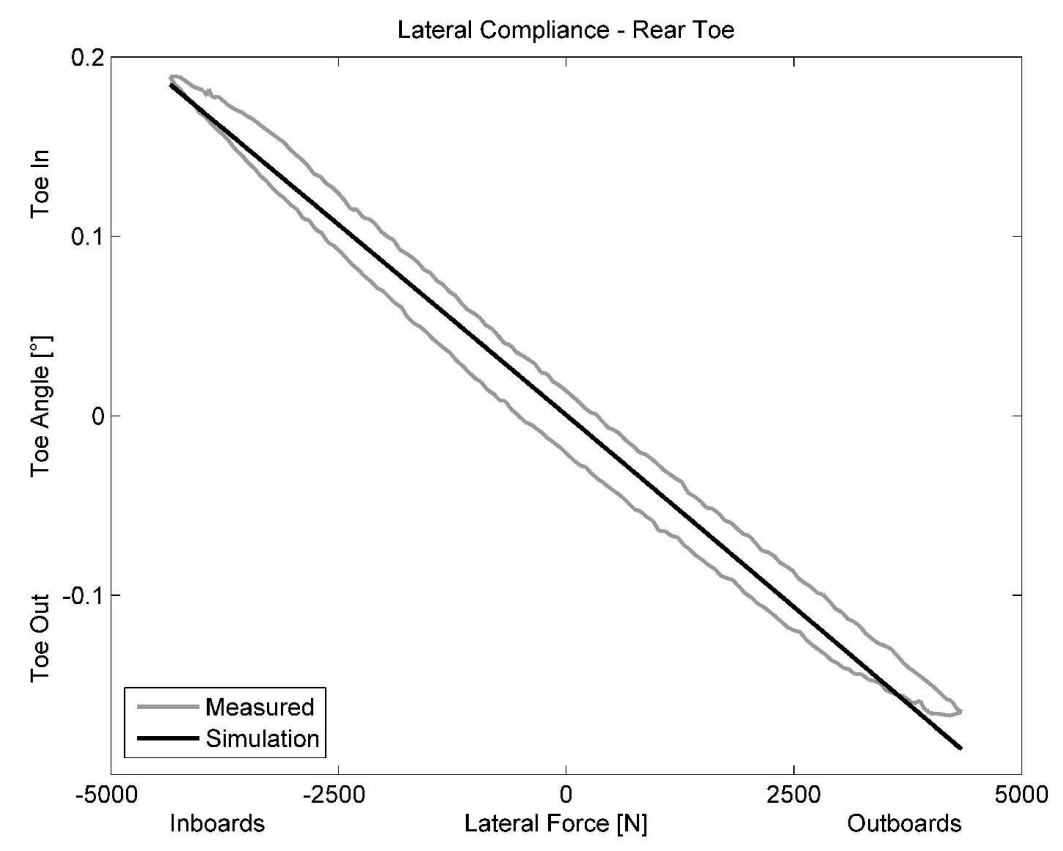

Figure 11. Example of model correlation - rear toe compliance. 


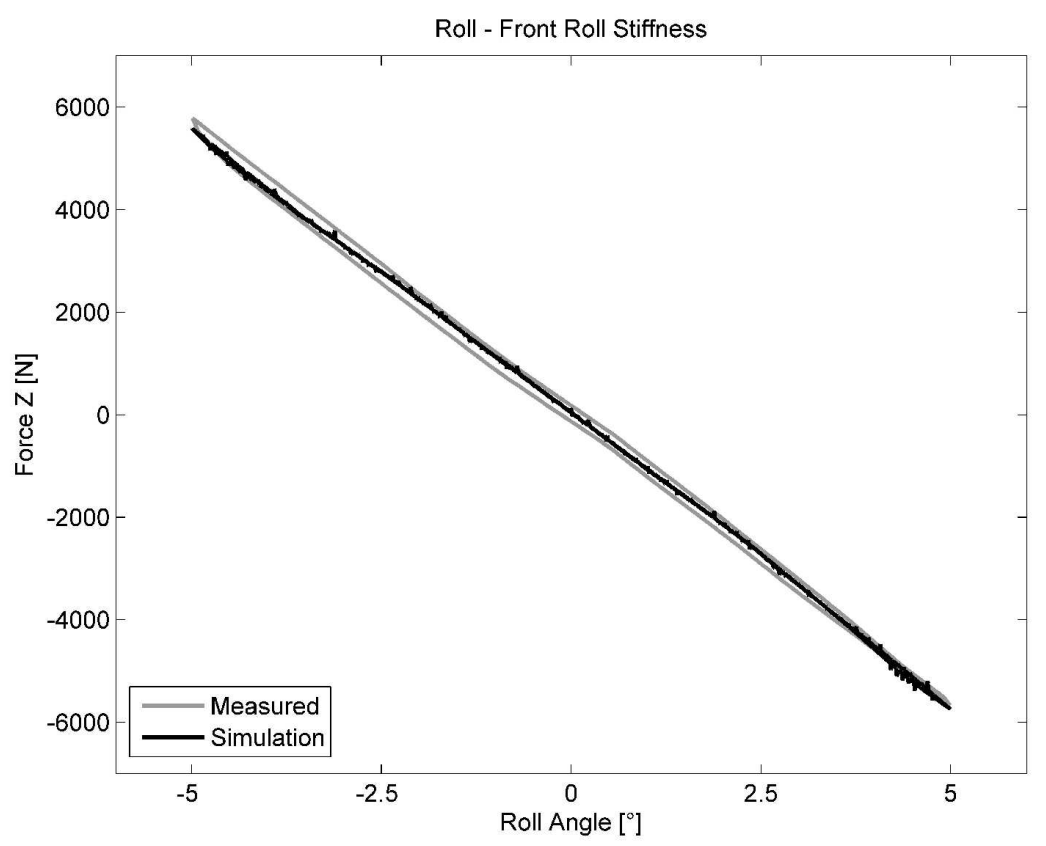

Figure 12. Example of model correlation - front roll stiffness.

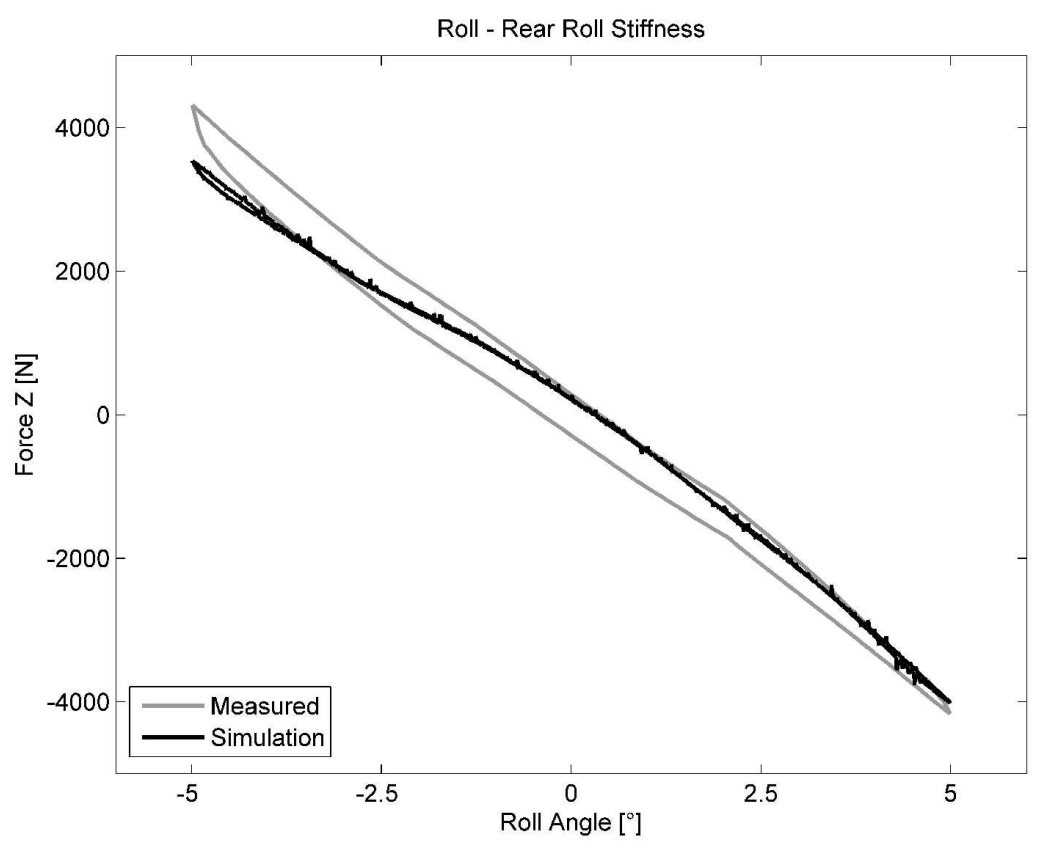

Figure 13. Example of model correlation - rear roll stiffness. 


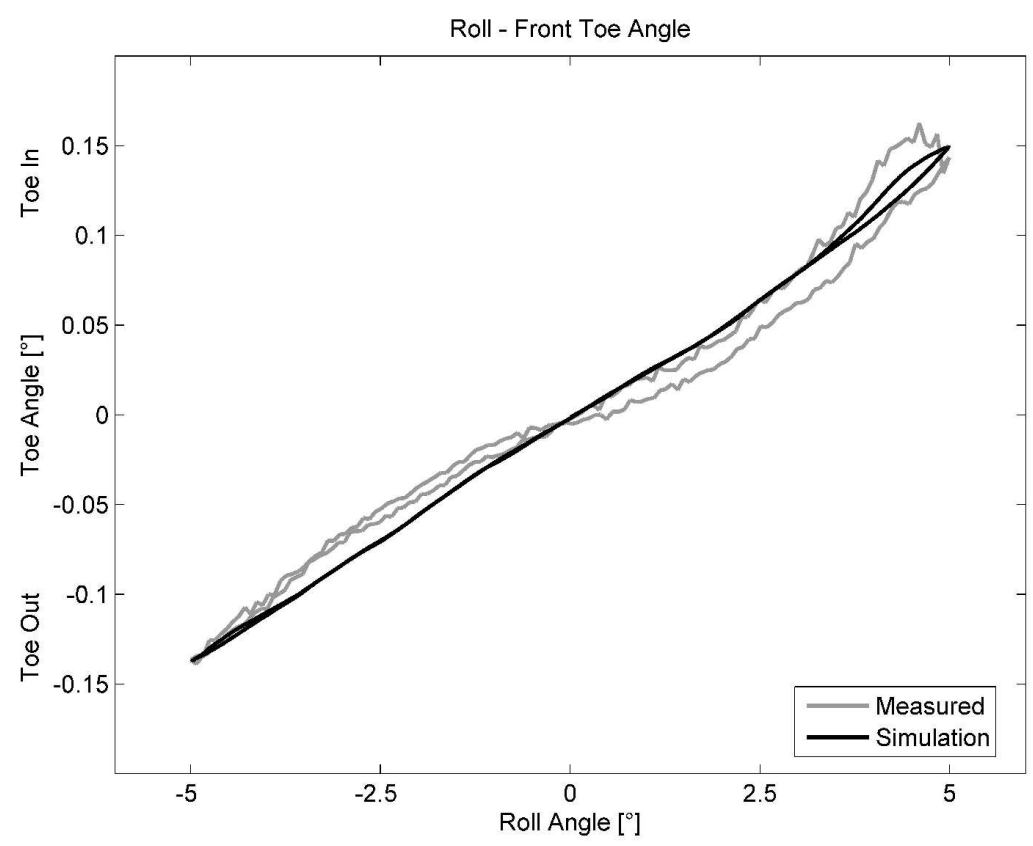

Figure 14. Example of model correlation - front roll steer.

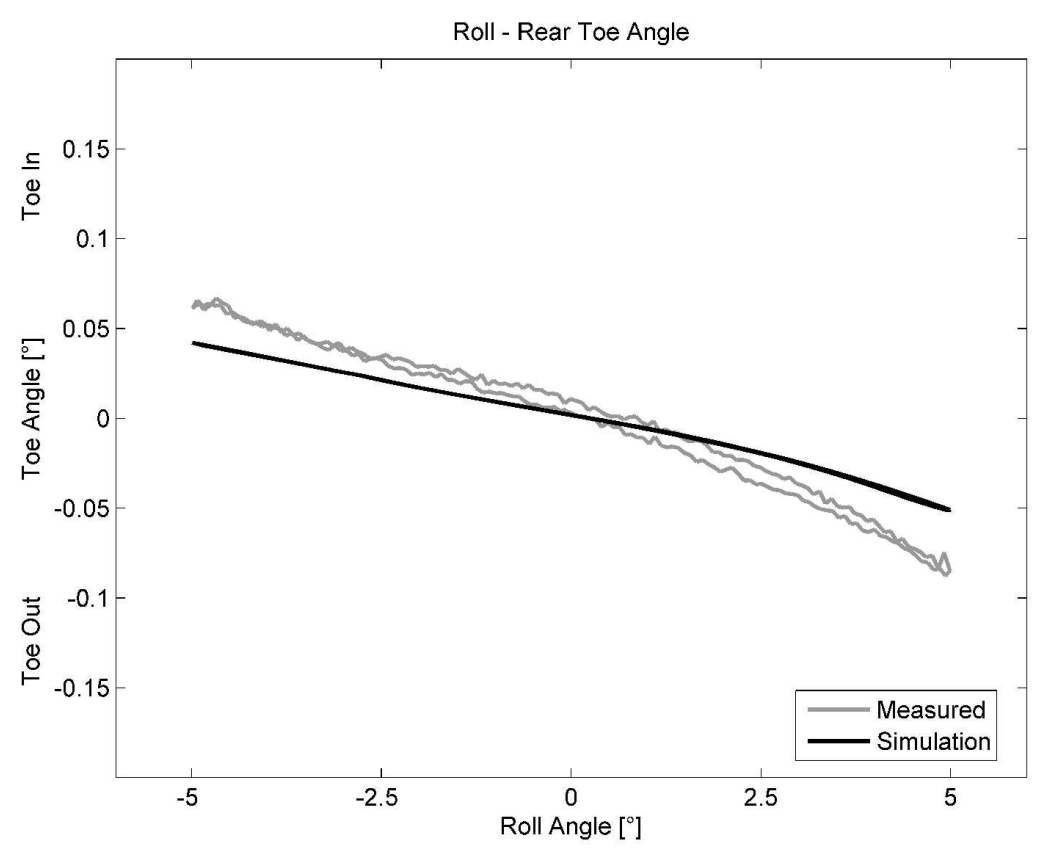

Figure 15. Example of model correlation - rear roll steer.

As can be seen, the vehicle model matches real life measurements well. This was achieved by making relatively small changes to the initial suspension geometry and bush compliances. 


\section{Design of Experiment}

Having set up a representative simulation model, design of experiment techniques $[19,20]$ were employed to study rollover propensity. A correctly designed experiment produces a set of results which can be analysed using statistical methods. Therefore, valid conclusions about the examined system can be drawn. Design of experiment also allows for simultaneous study of a large number of factors and their interactions [19]. The technique enables the user to reduce the number of experiments needed to draw conclusions, compared to trial and error studies or a "one factor at a time" approach. Another advantage of DoE is that once the experiments have been performed and results have been analysed, a response surface can be created to represent the relation between the inputs of the experiment and the response of the system [19]. This simplified model can be used to find an optimum set of parameters for the operation of the system. As the parameters used to mitigate vehicle rollover also influence other areas such as vehicle handling or ride comfort, these response surfaces can be used for multi-objective optimisation. DoE was implemented into SIMPACK using Qt script. The script can generate full factorial and fractional factorial designs, run the simulations, and generate the corresponding matrix of responses.

\subsection{Rollover metric}

When assessing rollover performance by simulation it is important to be able to detect the condition accurately. Especially in DoE studies where a large number of simulations are run, it is crucial to implement an efficient, yet dependable metric. A number of metrics can be used to assess the vehicle rollover resistance. Simple ones are derived from static analysis of a rigid vehicle as presented by Gillespie [21]. Based on such a model one can determine that rollover will occur if lateral accelerations exceed the 
rollover threshold:

$$
a_{y \lim }=\frac{g \cdot T}{2 \cdot H} \cdot \frac{1}{1+R_{\varphi} \cdot\left(1-\frac{H_{r}}{H}\right)}
$$

where $T$ - track, $H$ - height of CoG, $a_{y \text { lim }}$ - lateral acceleration rollover threshold, $R_{\phi}$ - rate of roll angle change with lateral acceleration, $H_{r}$ - roll centre height

A more sophisticated variation of the rollover threshold was presented by Jin et al. [4]. The authors proposed a Dynamic Stability Factor ( $D S F)$ in order to derive the lateral acceleration threshold:

$$
\begin{aligned}
& D S F=\frac{T}{2 H}- \\
& \frac{U^{2} \cdot m_{s} \cdot h^{2} \cdot \delta}{L \cdot H \cdot\left(k_{\phi}-m_{s} \cdot h \cdot g\right) \cdot\left\{1-\left(\frac{m \cdot U^{2}}{L^{2}}\right) \cdot\left[\frac{a}{2 k_{r}}-\frac{b}{2 k_{f} \cdot \cos \delta}\right]-\frac{U^{2} \cdot m_{s} \cdot h \cdot\left(c_{f}-c_{r}\right)}{L \cdot\left(k_{\phi}-m_{s} \cdot g \cdot h\right)}\right\}},
\end{aligned}
$$

so that the rollover threshold is:

$$
a_{y \lim }=g \cdot D S F
$$

The DSF takes into account such properties as roll stiffness $\left(k_{\phi}\right)$, height of CoG measured from the road $(H)$, height of the CG measured from the roll centre $(h)$, forward speed of the vehicle $(U)$, tyre cornering stiffness $\left(k_{f}, k_{r}\right)$, steering coefficients induced by roll $\left(c_{f}, c_{r}\right)$, sprung mass $\left(m_{s}\right)$, total mass $(m)$, steering angle of front wheels $(\delta)$, wheelbase of the vehicle $(L)$, longitudinal position of the $\mathrm{CoG}$ $(a, b)$. 
Other authors developed rollover stability based on the momentum conservation method, e.g. Eger et al. [22]. The stability boundary derived from phase plane analysis takes the form:

$$
\begin{gathered}
\omega_{x} \leq \sqrt{\frac{2 \cdot m \cdot g \cdot r \cdot\left[1-\cos \left(\kappa-\varphi_{x}\right)\right]}{\theta_{x}+m \cdot r^{2} \cdot \sin ^{2}\left(\kappa-\varphi_{x}\right)}} \\
\left|\varphi_{x}\right| \leq \kappa
\end{gathered}
$$

where $\omega_{x}$ - roll velocity, $m$ - mass, $r$ - distance from pivot point to $\mathrm{CoG}, \varphi_{x}$ - roll

angle, $\kappa=\operatorname{atan}\left(\frac{\mathrm{z}}{\mathrm{h}}\right)$ - tip angle, $\theta_{x}-$ roll inertia, $z-$ vehicle half-track width

The above mentioned rollover metrics are useful in estimating the vehicle's rollover resistance or predicting impending rollover, by performing static/quasi-static analysis to the non-linear vehicle model developed herein. However they are not a direct measure of rollover. Rollover metrics used for testing physical vehicles often involve sudden steering wheel inputs at constant vehicle velocity such as the double lane change test performed by Teknikens Värld [23] or the ISO 3888 Part 2 standard. Other types of manoeuvres used for assessing rollover propensity are the J-turn or fishhook. The evaluation of various open and closed loop manoeuvres in the context of assessing vehicle rollover propensity has been summarised in the NHTSA report DOT HS 809513 [24]. Two manoeuvres were regarded as most suited for this task; Roll Rate Feedback Fishhook and J-turn. During the evaluation, rollover propensity was characterised by monitoring the vehicle's entry velocity at which two wheel lift off occurred.

In an effort to gain additional insight into rollover dynamics and evaluate the use of two wheel lift off as an indicator of imminent rollover, a brief study of stability was 
carried out. From a purely qualitative point of view, the phase plane trajectory (PPT) of the roll velocity versus roll displacement was employed. The J-turn manoeuvre provided a suitable starting point. The upper half of Figure 16 illustrates the roll velocity plotted against roll displacement for one of the manoeuvres that did result in rollover. In the lower part of the same figure, the vertical tyre forces are presented as a function of time. The resulting PPT diagram resembles closely that of a pendulum [25]. Starting from the origin of the reference frame, both the roll angle and roll velocity increase as a result of the steering excitation. The roll velocity reaches a peak after which it reduces to almost generate a critical saddle point at approximately $6.3^{\circ}$ of roll angle. For an appropriately smaller forward velocity, a mathematically perfect saddle point would have been achieved whereby the roll speed would have reached zero and at that point the PPT diagram would have been non differentiable. This point would have been a point of unstable equilibrium, directly equivalent to the case of a pendulum resting in the inverted position. By establishing the point in time when the approximate saddle point is reached, it becomes evident that this is also the point when both inside tyres lose their contact with the ground. This point is clearly depicted in the lower part of Figure 16.

Further understanding of stability can be gained by observing the eigeinvalues of the linearised system as it progresses slowly through an approximately steady-state manoeuvre, where the lateral acceleration increases gradually. The steady-state condition is required so that it is possible to isolate a number of trim points, about which the system can be linearised and its eigenvalues obtained to establish stability, based on Liapunov's indirect method [26]. In this context, the previously used transient test case is inappropriate. Instead, the case of a vehicle travelling forward with a constant velocity and a steering controller tracking the required roll angle is used. To avoid 
traction problems and the need for a locked or active differential, a PID controller calculates the necessary thrust which is applied in the form of a force at the centre of mass of the vehicle. Thus the forward speed is maintained constant without altering the behaviour of the tyres and with minimal influence on the overall dynamics of the vehicle. The PID steering controller is used to find equilibrium conditions for a range of discrete roll angles. Once the equilibrium is achieved, the steering controller is deactivated and eigenvalues are calculated. For this test the forward speed was set to 30 $\mathrm{m} / \mathrm{s}$. As mentioned already, it is much more difficult to induce rollover by a quasisteady state manoeuvre, therefore for the purpose of this simulation the coefficient of friction was set equal to 1.6 .

The migration of eigenvalues as a result of increasing the roll-angle is shown in Figure 17. As the vehicle contains 165 degrees of freedom and an additional 15 internal states for each tyre, the total number of eigenvalues is substantial. Therefore only real values of roll mode are shown in Figure 17. The eigenvalue results were compared with the number of tyres in contact with the road.

It is evident that the transition to unstable behaviour coincides with the lift off of both inside tyres. 
2

3

4

5

6

7

8

9

10

11

12

13

14

15

16

17

18

19

20

21

22

23

24

25

26

27

28

29

30

31

32

33

34

35

36

37

38

39

40

41

42

43

44

45

46

47

48

49

50

51

52

53

54

55

56

57

58

59

60
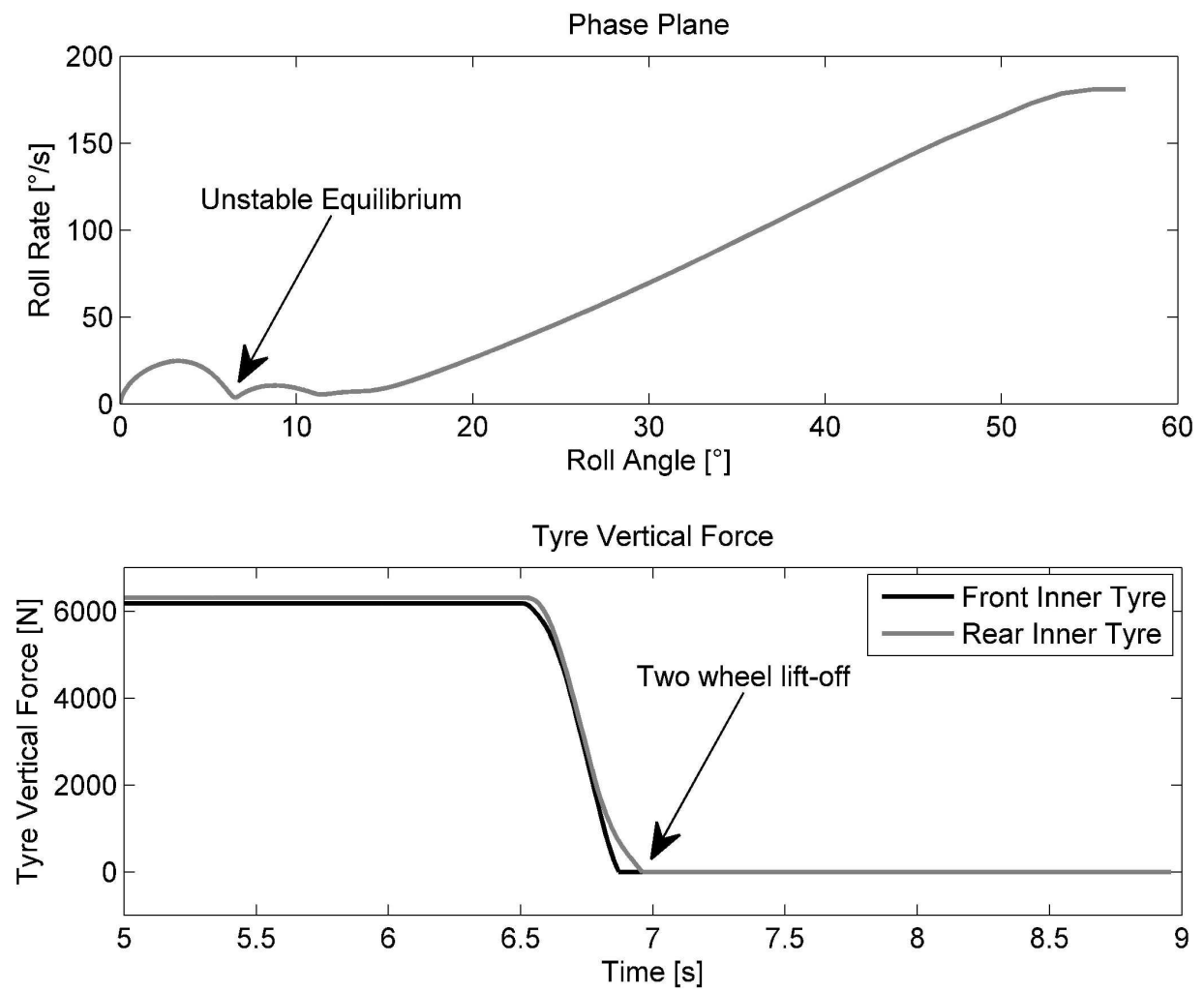

Figure 16. Roll angle - roll velocity phase plane and tyre vertical forces plotted in the time domain. 

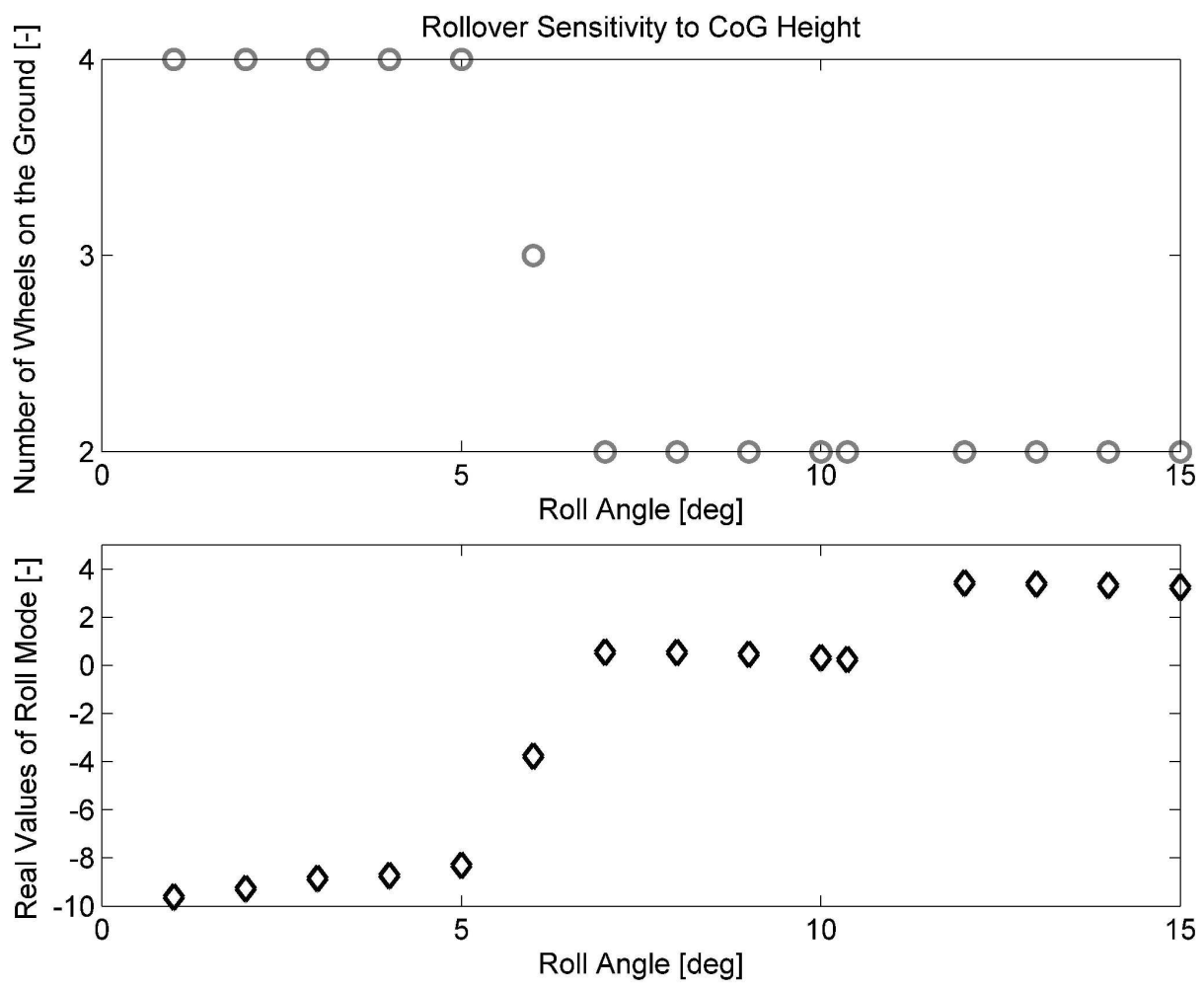

Figure 17 . Number of tyres in contact with road and roll mode stability during steady state manoeuvre.

Therefore, it can be concluded that tyre loss of contact represents a reliable metric of rollover. In theory, it would be expected that if the point of loss of contact is reached and if there is the slightest roll velocity residue at that point, the manoeuvre would definitely result in a rollover situation.

However, simulations show that loss of contact in combination with a roll velocity residue do not necessarily lead to rollover, even without corrective intervention from the driver. Non-linearities in tyre forces and suspension and further loss of forward speed in case of a coast-down test-case mean that the vehicle might return to a stable state, even if the loss of contact is reached with a roll velocity residue.

Therefore a more reliable indicator of whether vehicle rollover actually took place is necessary. Based on a large number of simulations, it was concluded that a 
1

2

3

4

5

6

7

8

9

10

11

12

13

14

15

16

17

18

19

20

21

22

23

24

25

26

27

28

29

30

31

32

33

34

35

36

37

38

39

40

41

42

43

44

45

46

47

48

49

50

51

52

53

54

55

56

57

58

59

60

rollover can be assumed if the roll angle exceeds $57.3^{\circ}$. It is important to note that this angle is specific to the nominal vehicle under investigation. For the purpose of this study the rollover propensity characterisation tests were carried out by launching the vehicle at a given velocity and after a short initial period of time when the vehicle is rolling freely, applying fixed steering input in the form of a step (steep ramp) steer (see Figure 9). Vehicle rollover or its absence is detected and a new launch velocity is chosen. The process is repeated until critical rollover velocity $V_{\text {Critical }}$ is found.

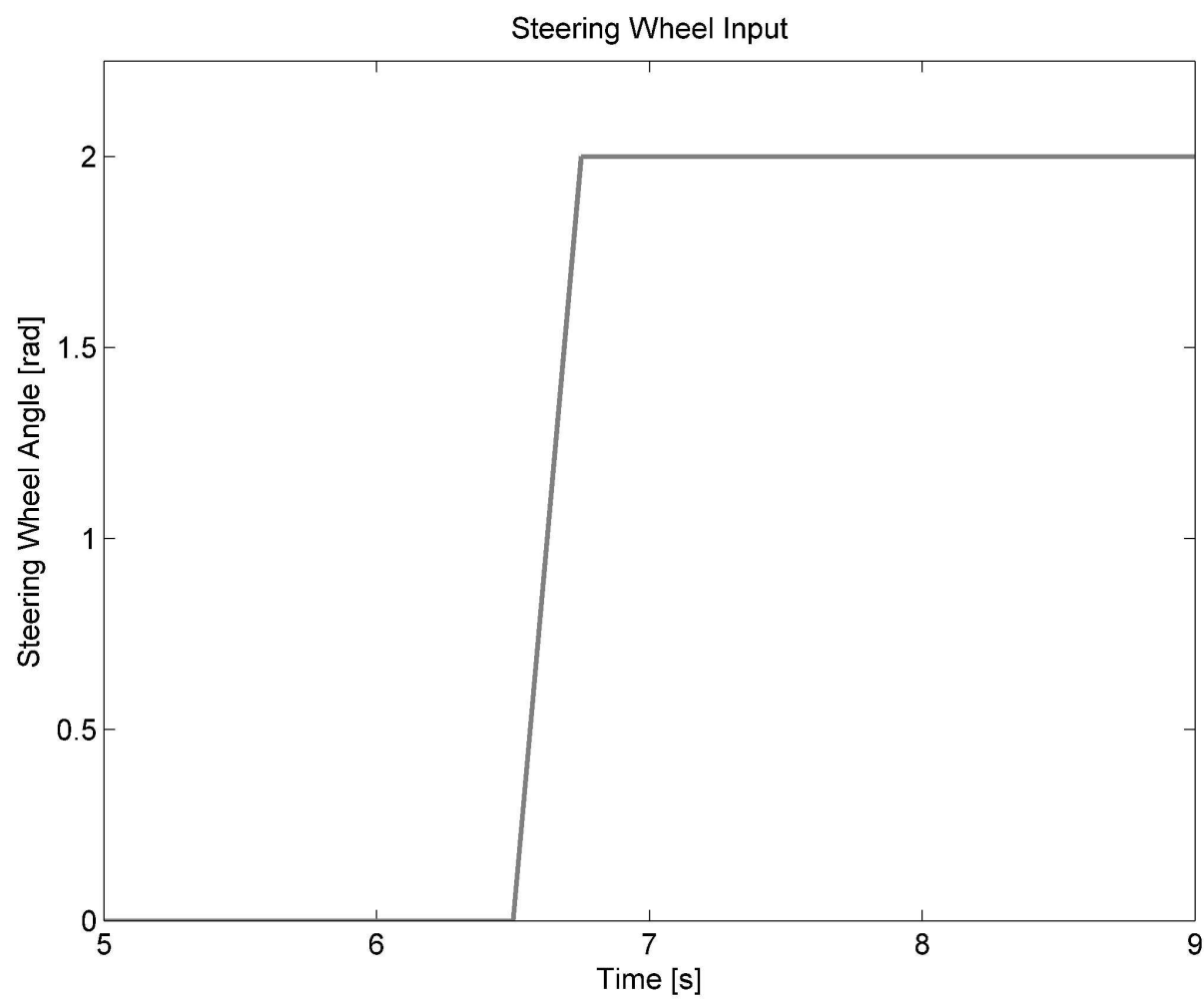

Figure 18. Steering wheel input used for DoE study.

\subsection{Area of high rollover sensitivity}

Having selected the above metric and in order to achieve a good spread of critical rollover velocity during the DoE, a range of friction scaling factors resulting in high critical velocity sensitivity had to be found. This was necessary as vehicle rollover is 
very sensitive to the level of available friction. Hence for high values of the friction scaling factor the spread of critical velocities would be very low, whereas for low values, vehicle rollover is likely not to occur at all. In order to further amplify roll-over sensitivity, an additional mass of $180 \mathrm{~kg}$ was placed above the vehicle's roof line.

In line with the above considerations, a relationship between vehicle critical rollover velocity and friction scaling factor was found. Firstly the friction scaling factor was varied from 1.1 to 1.9 in steps of 0.025 . For each factor a critical rollover velocity was found from values between $15 \mathrm{~m} / \mathrm{s}$ and $55 \mathrm{~m} / \mathrm{s}$ with a tolerance of $0.078125 \mathrm{~m} / \mathrm{s}$ resulting from the iterative nature of the search algorithm used to find the critical rollover velocity. In the second step the friction factor was varied between 1.35 to 1.45 in steps of 0.005 in order to improve the resolution of the results. The relationship between critical velocity and friction scaling factor is shown in fig. 5. A friction scaling factor of 1.375 was chosen for further investigation as it offered good critical rollover velocity sensitivity.

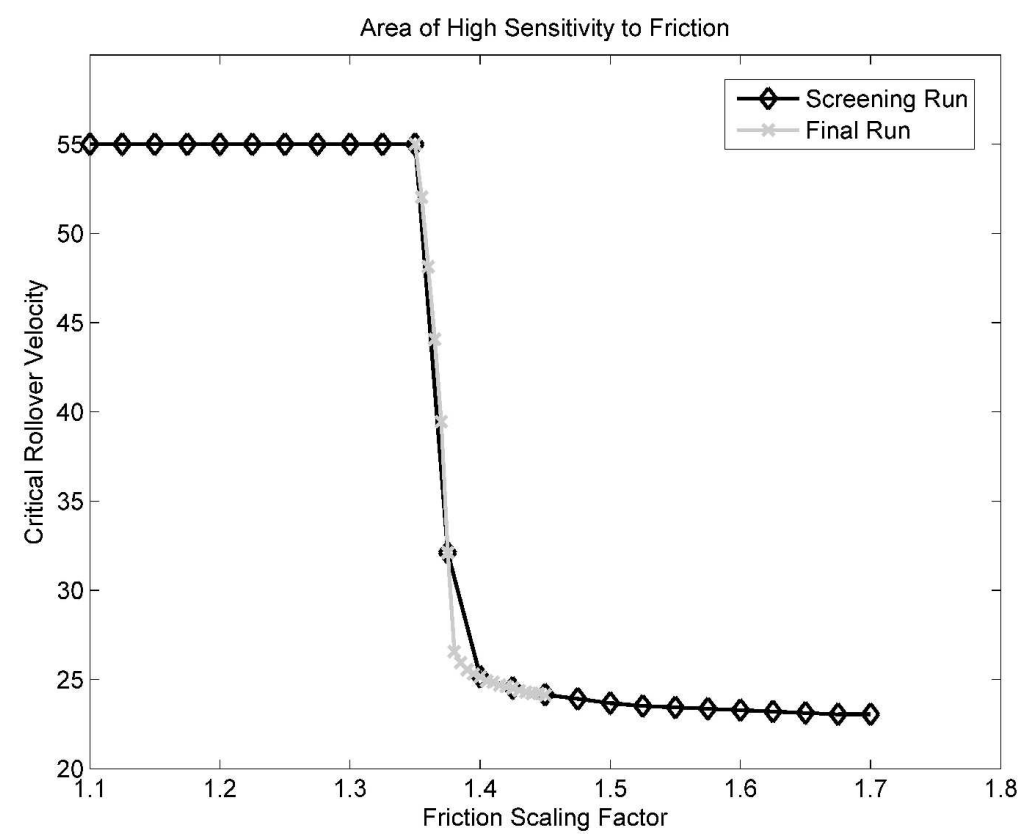

Figure 19. Relation between critical rollover velocity and friction scaling factor. 


\subsection{DoE results}

A DoE investigation was first performed to study the influence of tyre properties on vehicle rollover. Due to its empirical nature MF tyre 6.1 offers a good way of modifying tyre properties by changing tyre factors. From the list of all factors used to define tyre properties the following seven were of particular interest:

- $\lambda_{K y \alpha}-$ Scale factor of cornering stiffness

- $\lambda_{M x} \quad$ - Scale factor of overturning moment

- $\lambda_{\mu x} \quad$ - Scale factor of longitudinal peak friction coefficient

- $\lambda_{\mu y} \quad$ - Scale factor of lateral peak friction coefficient

- $\lambda_{y \gamma} \quad$ - Scale factor of camber stiffness

- $K_{z} \quad$ - Tyre vertical stiffness

- $p_{D y 2}-$ Variation of lateral friction with load

In order to keep the responses linear it was decided to set the upper and lower limits of factors at only $+/-1 \%$ from their nominal values. This applies to all factors apart from $\lambda_{\mu x}$ and $\lambda_{y \gamma}$ which were varied by $+/-0.2 \%$ due to the high sensitivity of the vehicle to tyre friction. In order to reduce the number of runs, fractional factorial design was chosen with design generators $\mathrm{E}=\mathrm{ABC}, \mathrm{F}=\mathrm{BCD}$ and $\mathrm{G}=\mathrm{ACD}$. The design matrix obtained is given in Table 2.

\begin{tabular}{r|ccccccc} 
Treatment & \multicolumn{7}{|c}{ Factorial Effect } \\
& A & B & C & D & E & F & G \\
\hline (1) & -1 & -1 & -1 & -1 & -1 & -1 & -1 \\
aeg & 1 & -1 & -1 & -1 & 1 & -1 & 1 \\
bef & -1 & 1 & -1 & -1 & 1 & 1 & -1
\end{tabular}


Table 2. Design matrix - geometric notation.

This design ensures that no main factor is aliased to any two-factor interaction and only factors $\mathrm{E}, \mathrm{F}$ and $\mathrm{G}$ are aliased with three-factor interactions. The following two-factor interactions are aliased with each other:

$$
\begin{aligned}
& A B=C E=F G \\
& A C=B E=D G \\
& A D=C G=E F \\
& A E=B C=D F \\
& A F=B G=D E \\
& A G=B F=C D \\
& B D=C F=E G
\end{aligned}
$$




$$
B E=A C=D G
$$

The results of all the runs are given in Table 3 .

\begin{tabular}{r|c} 
Treatment & Critical Rollover \\
velocity \\
{$[\mathrm{m} / \mathrm{s}]$}
\end{tabular}

Table 3. Vehicle model response to all studied treatments.

Based on these results statistical analysis was used to determine the influence of each factor. Firstly, contrasts (i.e. the total effects) for each factor were calculated using the geometric notation from Table 2. The contrasts were found by using the plus and minus signs in the factorial effects column and placing them in front of the response for each treatment they refer to. For example a contrast for the factor A equals: 


$$
\begin{aligned}
& \text { Contrast }_{A}=(-(1)+a e g-b e f+a b c f g-c e f g+a c f-b c g+a b c e-d f g \\
& +a d e f-b d e g+a b d-c d e+a c d g-b c d f+a b c d e f g)
\end{aligned}
$$

Therefore the total effect of factor A which is "Scale factor of cornering stiffness" equals -3.515625 for all runs. In order to determine the effect of factor $A$, the value of total effect of factor A needs to be divided by $n 2^{k-p}$ where $\mathrm{n}$ - number of repetitions, $\mathrm{k}$ - number of investigated factors, $\mathrm{p}$ - size of fraction, which is equal to the number of runs performed in this experiment. The values of effects for each factor are given in Table 4.

Factor code Factor name Effect Variation +/- Comment

$\begin{array}{lllll}\text { A } & \lambda_{K y \alpha} & -0.4395 & 1.0 \% & \text { Scale factor of cornering stiffness } \\ \text { B } & \lambda_{M x} & -2.7051 & 1.0 \% & \text { Scale factor of overturning moment } \\ \text { C } & \lambda_{\mu x} & -0.2832 & 0.2 \% & \text { Scale factor of long. peak friction coefficient } \\ \text { D } & \lambda_{\mu y} & -6.3574 & 0.2 \% & \text { Scale factor of lat. peak friction coefficient } \\ \text { E } & \lambda_{y \gamma} & 7.2168 & 1.0 \% & \text { Scale factor of camber stiffness } \\ \text { F } & K_{z} & -1.2793 & 1.0 \% & \text { Tyre vertical stiffness } \\ \text { G } & p_{D y 2} & -5.9668 & 1.0 \% & \text { Variation of lat. friction } \mu_{y} \text { with load }\end{array}$

Table 4. Effect of tyre properties on critical vehicle rollover velocity.

The study shows that the most influential tyre properties on vehicle rollover are:

(1) peak friction coeff. (D) - N.B. this factor was varied by $+/-0.2 \%$

(2) camber stiffness (E)

(3) friction variation with load (G)

(4) overturning moment (B)

(5) tyre vertical stiffness (F) 
The influence of tyre cornering stiffness and friction coefficient in the longitudinal direction was found to be relatively small. The influence of most factor interactions was also relatively weak compared to the influence of the main factors themselves. However an aliased interaction of $A F=B G=D E$ is significant and should be investigated in further studies. This interaction reveals synergy between independent tyre parameters in the way in which they affect rollover.

Based on values of effects a response surface model was created. The comparison of responses generated using the response surface model and multi-body model are shown in Table 5. It can be seen that this simplified model fits the results from the multibody model very well.

\begin{tabular}{r|ccc}
\multicolumn{4}{c}{ Critical rollover velocity $V_{\text {Critical }}$} \\
Treatment & $\begin{array}{c}\text { Actual value } \\
{[\mathrm{m} / \mathrm{s}]}\end{array}$ & $\begin{array}{c}\text { Predicted value } \\
{[\mathrm{m} / \mathrm{s}]}\end{array}$ & $\begin{array}{c}\text { Residual } \\
{[\mathrm{m} / \mathrm{s}]}\end{array}$ \\
\hline $\begin{array}{r}(1) \\
\text { aeg }\end{array}$ & 36.953 & 37.490 & -0.537 \\
bef & 38.281 & 38.301 & -0.020 \\
abfg & 42.344 & 40.723 & 1.621 \\
cefg & 36.797 & 27.100 & -0.303 \\
acf & 36.406 & 37.178 & -0.771 \\
bcg & 34.453 & 35.488 & -1.035 \\
abce & 27.578 & 28.535 & -0.957 \\
dfg & 43.281 & 41.279 & 2.002 \\
25.938 & 23.887 & 2.051 \\
adef & 35.625 & 36.631 & -1.006 \\
bdeg & 28.594 & 29.678 & -1.084 \\
abd & 27.266 & 27.988 & -0.723 \\
cde & 37.813 & 38.066 & -0.254 \\
& & &
\end{tabular}




\begin{tabular}{r|rrr} 
acdg & 26.016 & 24.443 & 1.572 \\
bcdf & 26.797 & 26.865 & -0.068 \\
abcdefg & 27.188 & 27.676 & -0.488
\end{tabular}

Table 5. Comparison between simulation and response surface results generated from the main effects, only.

\section{KnC sensitivity study results}

\subsection{Methodology}

In order to establish the link between $\mathrm{K} \& \mathrm{C}$ properties and rollover propensity using design of experiment methodology, direct control over the input to the experiment, in this case $\mathrm{K} \& \mathrm{C}$ metrics, is required. However, as these metrics are a function of suspension geometry and component stiffnesses, they cannot be changed independently in a simple manner, as a single geometrical or compliance change influences all characteristics simultaneously. Attempts to change just one characteristic while keeping others unchanged have been made successfully in the past; however, they usually involve a large number of iterations of geometry and stiffnesses before such change is achieved. As the purpose of this study is to find the most influential $\mathrm{K} \& \mathrm{C}$ characteristics and establish the link between them and rollover resistance, such an approach was regarded as ineffective and too time consuming. Therefore, a novel approach based on statistical tools is proposed here. The method can be split into four separate stages. Firstly a large number of iterations with different suspension geometries and component stiffnesses are generated using a space filling method such as a Latin Hypercube. In the second stage, each of the above-mentioned iterations is characterised using a number of $\mathrm{K} \& \mathrm{C}$ metrics. In the third stage, for each of the above iterations a rollover propensity characterised by rollover critical velocity is found. Finally a regression model is fitted using the set of $\mathrm{K} \& \mathrm{C}$ characteristics as an input, and rollover 
propensity as the response. Such a process creates a link between $K \& C$ characteristics of the suspension and rollover propensity, despite not having direct control over the previously generated characteristics.

Before starting the experiment, the factors influencing the $\mathrm{K} \& \mathrm{C}$ characteristics had to be defined. The factors chosen as the most influential were:

- $\quad$ suspension arm and links hardpoint positions $(\mathrm{x}, \mathrm{y}, \mathrm{z})$ - primarily affecting kinematics

- $\quad$ suspension bushes and ball joint stiffness - primarily affecting compliance; in order to reduce the number of inputs in the first stage of the experiment, stiffness at only one end of each link was varied

- $\quad$ spring stiffness, spring aid nonlinear characteristic and clearance, rebound spring stiffness and clearance - primarily affecting wheel rate characteristic and roll stiffness

- $\quad$ anti-roll bar stiffness - primarily affecting roll stiffness

As factors at both front and rear suspensions were chosen as an inputs, the total number of factors equalled 98 input parameters to the design of experiment.

As the number of inputs to the first stage of the experiment is large, a Latin Hypercube was chosen to arrange them in an input matrix. Matlab was used to generate a Latin Hypercube with coded variables varying between 0 and 1. The Latin Hypercube generated varied values of 98 independent variables at 100 different value ranges, in 1000 runs. In stage two of the experiment, a number of $\mathrm{K} \& \mathrm{C}$ characteristics had to be captured. Four K\&C tests were chosen to generate these characteristics; vertical test, roll test with anti-roll bars, roll test without anti-roll bars, and lateral compliance test. A number of key characteristics were chosen from each test: 
- Kinematics:

- Camber vs. wheel centre vertical displacement

○ Toe vs. wheel centre vertical displacement

○ Contact patch force vs. wheel centre vertical displacement

-Wheel centre lateral displacement vs. wheel centre vertical displacement

- Kinematic roll centre height vs. wheel centre vertical displacement

- Lateral in phase compliance test:

- Camber vs. lateral force

- Toe vs. lateral force

○ Jacking i.e. vertical vs. lateral force

- Wheel centre lateral displacement vs. lateral force

- Roll test with and without anti-roll bars (maintaining constant front to rear load distribution);

O On-centre wheel rate in roll

- Anti-roll bar contribution to roll stiffness (combined result from test with and without anti-roll bar)

In order to be able to capture the $\mathrm{K} \& \mathrm{C}$ characteristics in an easy-to-process way, a number of metrics were developed. For most metrics, 3 points on the characteristics, start, middle and end, were recorded and the $2^{\text {nd }}$ order polynomial was fitted. This resulted in two key coefficients, the first describing the linear gradient, the second describing the nonlinearity.

For more complex characteristics such as suspension stiffness in bump (effects of main spring, rebound spring and nonlinear spring aid), 5 equally spaced points were captured. Based on these points, 4 linear instantaneous stiffnesses were derived, resulting in 4 metrics from this test. Additionally, anti-roll bar contribution to roll 
stiffness was described by a single number reflecting the additional roll stiffness due to the anti-roll bar.

Based on the results of these 4 simulations, the vehicle's K\&C from front and rear axles is characterised using 58 different metrics. The list of all metrics is given in Table 6 .

\begin{tabular}{|c|c|c|}
\hline Symbol & Test & Metric \\
\hline$\gamma_{V}$ & Vertical Kinematics & Linear dependency of camber angle $\gamma$ on wheel travel \\
\hline$\gamma_{V^{2}}$ & Vertical Kinematics & Quadratic dependency of camber angle $\gamma$ on wheel travel \\
\hline$K_{V 2 r}$ & Vertical Kinematics & Suspension rate in second half of rebound travel \\
\hline$K_{V 1 r}$ & Vertical Kinematics & Suspension rate in first half of rebound travel \\
\hline$K_{V 1 b}$ & Vertical Kinematics & Suspension rate in first half of bump travel \\
\hline$K_{V 2 b}$ & Vertical Kinematics & Suspension rate in second half of bump travel \\
\hline$\alpha_{V}$ & Vertical Kinematics & Linear dependency of toe angle $\alpha$ on wheel travel \\
\hline$\alpha_{V^{2}}$ & Vertical Kinematics & Quadratic dependency of toe angle $\alpha$ on wheel travel \\
\hline$\rho_{V}$ & Vertical Kinematics & Kinematic roll centre height \\
\hline$\rho_{V 2}$ & Vertical Kinematics & Rate of change of kinematic roll centre height due to wheel travel \\
\hline$\psi_{V}$ & Vertical Kinematics & Linear dependency of wheel centre lateral position on wheel travel \\
\hline$\psi_{V^{2}}$ & Vertical Kinematics & $\begin{array}{l}\text { Quadratic dependency of wheel centre lateral position on wheel } \\
\text { travel }\end{array}$ \\
\hline$\gamma_{L}$ & Lateral Compliance & Linear dependency of camber angle $\gamma$ on lateral force at contact patch \\
\hline$\varphi_{L}$ & Lateral Compliance & Normalised jacking force due to lateral force at contact patch \\
\hline$\alpha_{L}$ & Lateral Compliance & Linear dependency of toe angle $\alpha$ on lateral force at contact patch \\
\hline$\psi_{L}$ & Lateral Compliance & $\begin{array}{l}\text { Linear dependency of wheel centre lateral position on lateral force at } \\
\text { contact patch }\end{array}$ \\
\hline$K_{R}$ & Roll Test with & Wheel rate in roll \\
\hline
\end{tabular}




$\begin{array}{ll} & \text { Anti-Roll Bars } \\ \zeta_{R} \quad \text { Roll Tests with and } & \text { Anti-roll bar contribution to wheel rate }\end{array}$

Table 6. $\mathrm{K} \& \mathrm{C}$ metrics employed in the experiment.

Suspension $\mathrm{K} \& \mathrm{C}$ characteristics can directly affect steering wheel ratio. In the earlier section of this paper focusing on finding the area of high sensitivity to tyre parameters and studying their effect on rollover, the steering wheel angle input in the step steer manoeuvre was fixed to $114.6^{\circ}$. Changing the steering ratio whilst keeping a fixed steering wheel angle would lead to the vehicle following a different path to the base model. This in turn has a direct influence on the vehicle's lateral acceleration and rollover critical speed. In order to compensate for this, a procedure for normalising the steering wheel input was implemented. The procedure is briefly described below.

After reading in factor levels corresponding to the given treatment, the vehicle model is set to travel on an initially straight road at $10 \mathrm{~m} / \mathrm{s}$. Vehicle speed remains constant thanks to a closed loop driveline controller driving all 4 wheels with an equal torque reacted at the vehicle body for the front wheels and rear subframe for the rear wheels. Similarly the vehicle model is also equipped with a simple closed loop steering controller which follows the road by reducing lateral path deviation at the front axle by controlling the steering wheel angle.

After an initial $65 \mathrm{~m}$ straight, the road on which the vehicle travels begins to turn right, and after $15 \mathrm{~m}$ the transition becomes a constant radius corner with the radius set to $29.317 \mathrm{~m}$. This radius corresponds to the radius at which a baseline vehicle would travel with a forward velocity of $10 \mathrm{~m} / \mathrm{s}$ and a steering wheel angle of $114.6^{\circ}$. The vehicle equipped with both driveline and steering controllers will, after settling down, reach a steady state constant radius condition. The steering wheel angle corresponding 
to this condition becomes the reference steering wheel angle and is later used to find the rollover critical speed.

This method of setting the reference steering wheel angle ensures that changes in steering wheel ratio due to modified suspension geometry are not influencing the rollover results. However, the method has a potential down side, in the fact that it also cancels out part of the influence of understeer gradient as the reference steering wheel angle is obtained at a lateral acceleration far from $0 \mathrm{~m} / \mathrm{s}^{2}$. In fact the lateral acceleration is $3.41 \mathrm{~m} / \mathrm{s}^{2}$, which corresponds to average cornering conditions. The reason why the reference steering wheel angle is set at such a condition is that, in reality, a driver is able to "map" the required steering wheel angle to vehicle speed and corner radius, and is therefore accounting for steering ratio and understeer gradient of a vehicle which he or she is driving.

Once the reference steering wheel angle has been found, it is then used as the final value of the step steer input used to determined rollover critical speed. The process of finding the rollover critical speed is the same as in the tyre DoE described in section 3. It consists of 11 runs at various vehicle start velocities varying between $15 \mathrm{~m} / \mathrm{s}$ and $55 \mathrm{~m} / \mathrm{s}$. The result of the process is the highest vehicle velocity at which it doesn't rollover.

Once both $\mathrm{K} \& \mathrm{C}$ metrics and corresponding rollover critical velocities have been found, outputs from both tests are linked using a response surface. This allows the effects to be statistically separated from each other, and rated in order of statistical significance.

The large number of inputs to the regression model meant that only the main factors could be assessed initially. Once all the insignificant factors have been excluded from the model, the effect of the interaction and second order terms were studied. An 
additional complication when fitting the regression model results from the fact that some of the metrics are dependent on each other, e.g.:

- $\quad$ suspension rate in bump and roll stiffness

- roll stiffness and anti-roll bar contribution to roll stiffness

- jacking force and kinematic roll centre height.

The fact that some variables are co-dependent makes the choice of terms in a statistical model somewhat more difficult. This is because inclusion of one parameter will affect the regression coefficient of another parameter.

To find the best set of parameters in the statistical model a step wise regression algorithm was used. The original step wise regression Matlab function was modified to base the decision on inclusion or exclusion of parameters not on p-values but on tstatistics.

In order to check how well a given set of potential K\&C metrics can be assembled together into a statistical model, a step wise regression was performed for different values of t-statistics and the plot of adjusted R-square vs. number of terms in the statistical model was generated. Such a graph can help to decide where the best compromise between model complexity and model accuracy is.

\subsection{Results}

The results of stepwise regression using the $\mathrm{K} \& \mathrm{C}$ metrics as an input and rollover critical velocity as an output are shown in the Table 7 and Figure 20. The stepwise regression has been performed for different values of t-statistics used to determine which metrics should be excluded or included in the statistical model. It is worth pointing out that stepwise regression was based on the initial model with all terms included. This resulted in better model fit than stepwise regression with no terms in the 
initial model.

\begin{tabular}{|c|c|c|c|c|c|c|c|c|c|}
\hline TSTAT & 0.001 & 1 & 2 & 3 & 4 & 5 & 6 & 7 & 8 \\
\hline Metric & \multicolumn{9}{|c|}{ Included in statistical model? } \\
\hline${ }^{F} \gamma_{V^{2}}$ & True & True & True & False & False & False & False & False & False \\
\hline${ }^{F} \gamma_{V}$ & True & True & True & True & True & True & True & True & True \\
\hline${ }^{F} K_{V 2 r}$ & True & True & False & False & False & False & False & False & False \\
\hline${ }^{F} K_{V 1 r}$ & True & True & True & True & True & True & True & True & True \\
\hline${ }^{F} K_{V 1 b}$ & True & True & True & True & True & True & False & False & False \\
\hline${ }^{F} K_{V 2 b}$ & True & True & True & True & True & False & False & False & False \\
\hline${ }^{F} \alpha_{V^{2}}$ & True & True & True & True & True & True & False & False & False \\
\hline${ }^{F} \alpha_{V}$ & True & False & False & False & False & False & False & False & False \\
\hline${ }^{F} \rho_{V 2}$ & True & False & False & False & False & False & False & False & False \\
\hline${ }^{F} \rho_{V}$ & True & False & False & False & False & False & False & False & False \\
\hline${ }^{F} \psi_{V^{2}}$ & True & False & False & False & False & False & False & False & False \\
\hline${ }^{F} \psi_{V}$ & True & True & True & True & True & True & True & True & False \\
\hline${ }^{R} \gamma_{V^{2}}$ & True & True & True & True & True & True & True & False & False \\
\hline${ }^{R} \gamma_{V}$ & True & True & True & True & True & True & True & False & False \\
\hline${ }^{R} K_{V 2 r}$ & True & False & False & False & False & False & False & False & False \\
\hline${ }^{R} K_{V 1 r}$ & True & True & True & True & False & False & False & False & False \\
\hline${ }^{R} K_{V 1 b}$ & True & True & True & True & True & True & True & True & True \\
\hline${ }^{R} K_{V 2 b}$ & True & False & False & False & False & False & False & False & False \\
\hline${ }^{R} \alpha_{V^{2}}$ & True & True & True & False & False & False & False & False & False \\
\hline
\end{tabular}


\begin{tabular}{|c|cccccc|c|c|c|}
${ }^{R} \alpha_{V}$ & True & True & True & True & False & False & False & True & False \\
${ }^{R} \psi_{V^{2}}$ & True & False & False & False & False & False & False & False & False
\end{tabular}

${ }^{R} \psi_{V} \quad$ True $\quad$ True True True True True True True False

${ }^{R} \rho_{V 2}$ True $\quad$ False False False False False False False False

${ }^{R} \rho_{V} \quad$ True True True True True True True False False

${ }^{F} \gamma_{L} \quad$ True True True True True True True True True

${ }^{F} \varphi_{L} \quad$ True $\quad$ False False False False False False False False

${ }^{F} \alpha_{L} \quad$ True False False False False False False False False

${ }^{F} \psi_{L} \quad$ True True True True True True False False False

${ }^{R} \gamma_{L}$ True True True True True True True True True

${ }^{R} \varphi_{L} \quad$ True True True True True True True True True

${ }^{R} \alpha_{L} \quad$ True True False False False False False False False

${ }^{R} \psi_{L} \quad$ True True False False False False False False False

${ }^{F} K_{R} \quad$ True True True True True True $\quad$ True True True

${ }^{R} K_{R} \quad$ True $\quad$ False False False False False False False False

${ }^{F} \zeta_{R}$ True True True False False False False False False

${ }^{R} \zeta_{R}$ True True False False False False False False False

\begin{tabular}{l|lllllllll}
$R^{2}$ & 0.8613 & 0.8605 & 0.8595 & 0.8569 & 0.8531 & 0.8506 & 0.8408 & 0.8360 & 0.8083
\end{tabular}

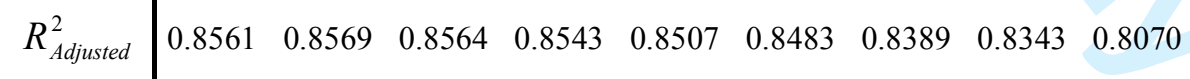

\begin{tabular}{l|lllllllll} 
No of terms & 36 & 25 & 21 & 18 & 16 & 15 & 12 & 10 & 7
\end{tabular}

Table 7. Summary of statistical models generated using stepwise regression.

The simplest model was obtained by stepwise regression with limit t-statistics set to 8 . It consisted of 7 main terms: 
1

2

3

4

5

6

7

8

9

10

11

12

13

14

15

16

17

18

19

20

21

22

23

24

25

26

27

28

29

30

31

32

33

34

35

36

37

38

39

40

41

42

43

44

45

46

47

48

49

50

51

52

53

54

55

56

57

58

59

60

- Front suspension rate on centre rebound

- Rear suspension rate on centre bump

- Front bump camber

- Front and rear camber compliance

- Rear jacking force

- Front roll stiffness on centre

However the quality of fit of this model measured by calculating $\mathrm{R}^{2}$ adjusted was only

0.807. A plot of $\mathrm{R}^{2}$ adjusted as a function of number of the model terms was used to find a compromise between model accuracy and complexity (Figure 20). A 16-term statistical model seems to fulfil this requirement fairly well. Apart from all metrics included in the 7-term model it additionally includes:

- Front suspension on centre bump rate and full bump rate

- Front bump toe nonlinearity

- Front wheel centre lateral travel with bump

- Rear camber compliance linearity and nonlinearity

- Rear wheel centre lateral travel with bump

- Rear kinematic roll centre height

- Front wheel centre compliance 


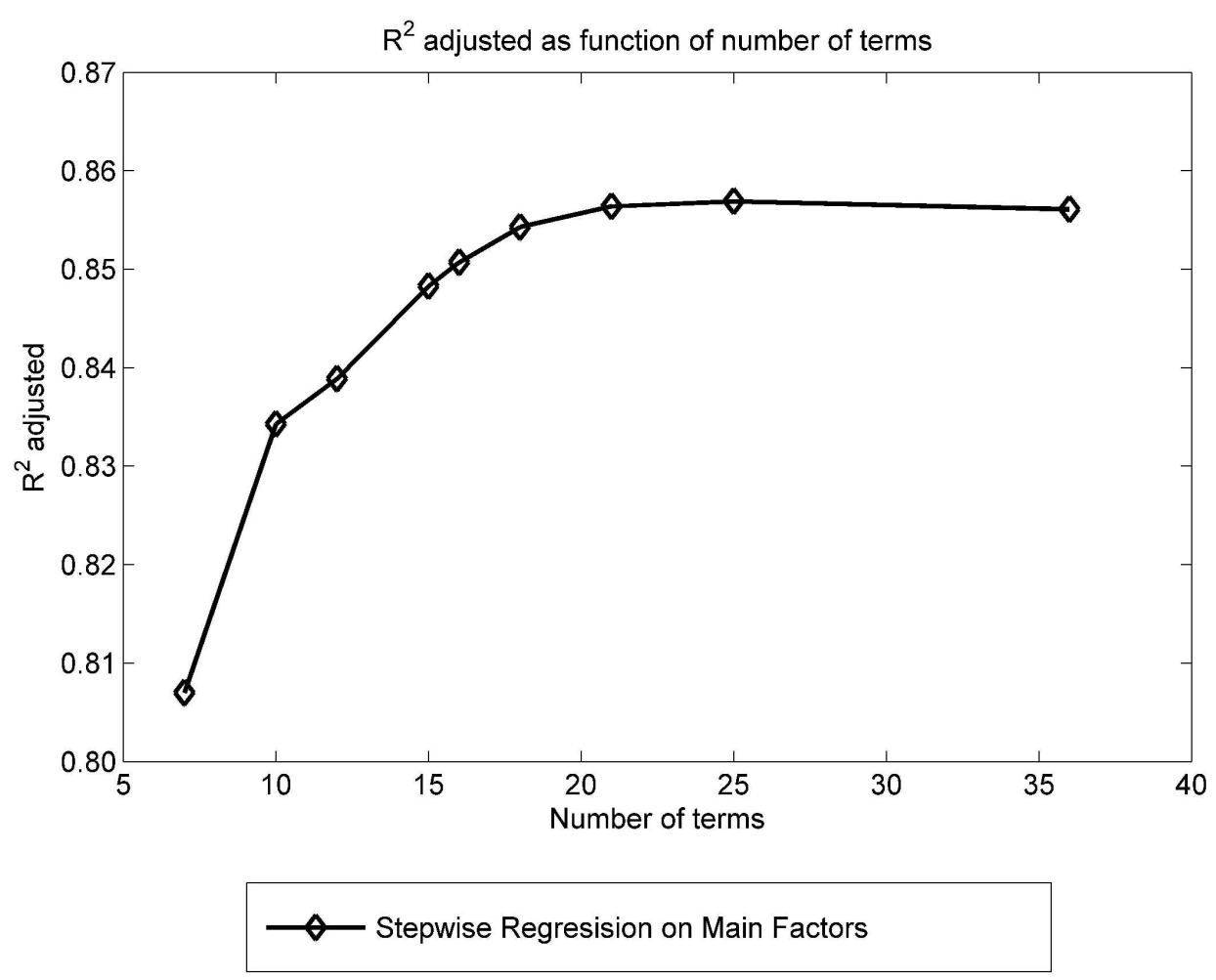

Figure 20. Relation between critical number of model terms and quality of fit.

In order to check the quality of the model constructed using stepwise regression, an algorithm testing all possible combinations of the 16 factor model was used. The number of 16 factor combinations available from 36 possible factors is $7.31 \mathrm{E}+09$. Calculating the adjusted $\mathrm{R}^{2}$ for all these models would take too long, so the number of factors in the initial pool hat to be reduced. To do that both forward and backward regression with t-statistics set to 2 was performed and if a factor was included in at least one of the two resulting models, it was included in the pool of potential factors. The result was 25 potential factors, which gives 2042975 combinations of 16-term models to test. The results of this study are shown in (Table 8) and (Figure 21). 


\begin{tabular}{|c|c|c|}
\hline & $\begin{array}{l}\text { Model from } \\
\text { stepwise } \\
\text { regression }\end{array}$ & $\begin{array}{c}\text { Best possible } \\
\text { model }\end{array}$ \\
\hline Metric & $\begin{array}{r}\text { Included } \mathrm{i} \\
\mathrm{mo}\end{array}$ & statistical \\
\hline${ }^{F} \gamma_{V^{2}}$ & False & False \\
\hline${ }^{F} \gamma_{V}$ & True & True \\
\hline${ }^{F} K_{V 2 r}$ & False & False \\
\hline${ }^{F} K_{V 1 r}$ & True & True \\
\hline${ }^{F} K_{V 1 b}$ & True & True \\
\hline${ }^{F} K_{V 2 b}$ & True & True \\
\hline${ }^{F} \alpha_{V^{2}}$ & True & True \\
\hline${ }^{F} \psi_{V}$ & True & True \\
\hline${ }^{F} \rho_{V}$ & False & False \\
\hline${ }^{R} \gamma_{V^{2}}$ & True & False \\
\hline${ }^{R} \gamma_{V}$ & True & True \\
\hline${ }^{R} K_{V 1 r}$ & False & False \\
\hline${ }^{R} K_{V 1 b}$ & True & True \\
\hline${ }^{R} K_{V 2 b}$ & False & False \\
\hline${ }^{R} \alpha_{V^{2}}$ & False & False \\
\hline${ }^{R} \alpha_{V}$ & False & True \\
\hline${ }^{R} \psi_{V^{2}}$ & False & False \\
\hline${ }^{R} \psi_{V}$ & True & True \\
\hline${ }^{R} \rho_{V}$ & True & True \\
\hline
\end{tabular}




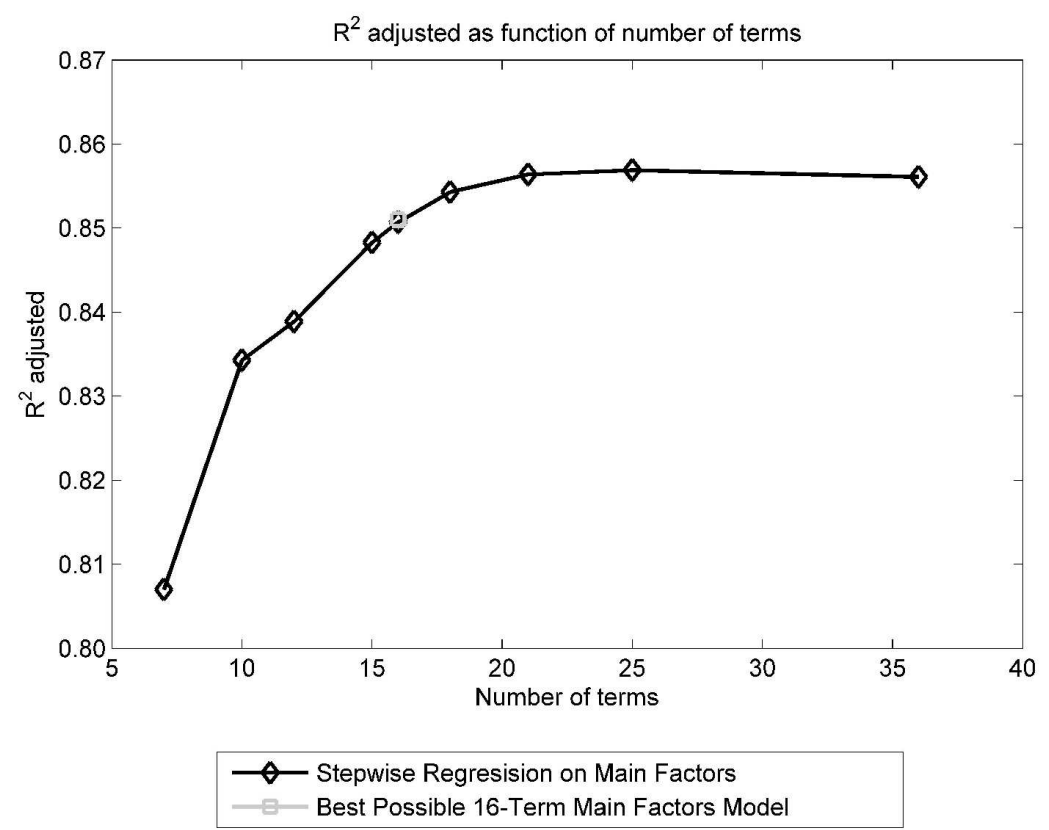

Figure 21. Comparison of models generated using stepwise regression and best possible model.

The best possible model found by testing all possible combinations was marginally better than the one chosen by stepwise regression with all terms included in 
the initial model. Moreover the only difference between the model generated by stepwise regression and the best possible model was one factor. This showed that stepwise regression with all terms included in the initial model is a very efficient way of finding well-fitting statistical models. Therefore in subsequent studies the stepwise regression starting with a full model was used.

So far all statistical models generated in this study were constructed of only main factors. In complex systems the interactions between the factors are a significant part of the observed process. Therefore in the next part of the study a number of models with interactions and squared terms were generated. As a basis for this, a best possible 16 term model was chosen. Based on the 16 terms included in the model, all possible $1^{\text {st }}$ order interactions and squared terms were generated resulting in a total of 152 potential model terms. To find the best model, the stepwise regression starting with a full model was employed, with an additional constraint ensuring that all 16 main effects are always included in the model. The achieved model fit has been shown in Table 9 and Figure 22.

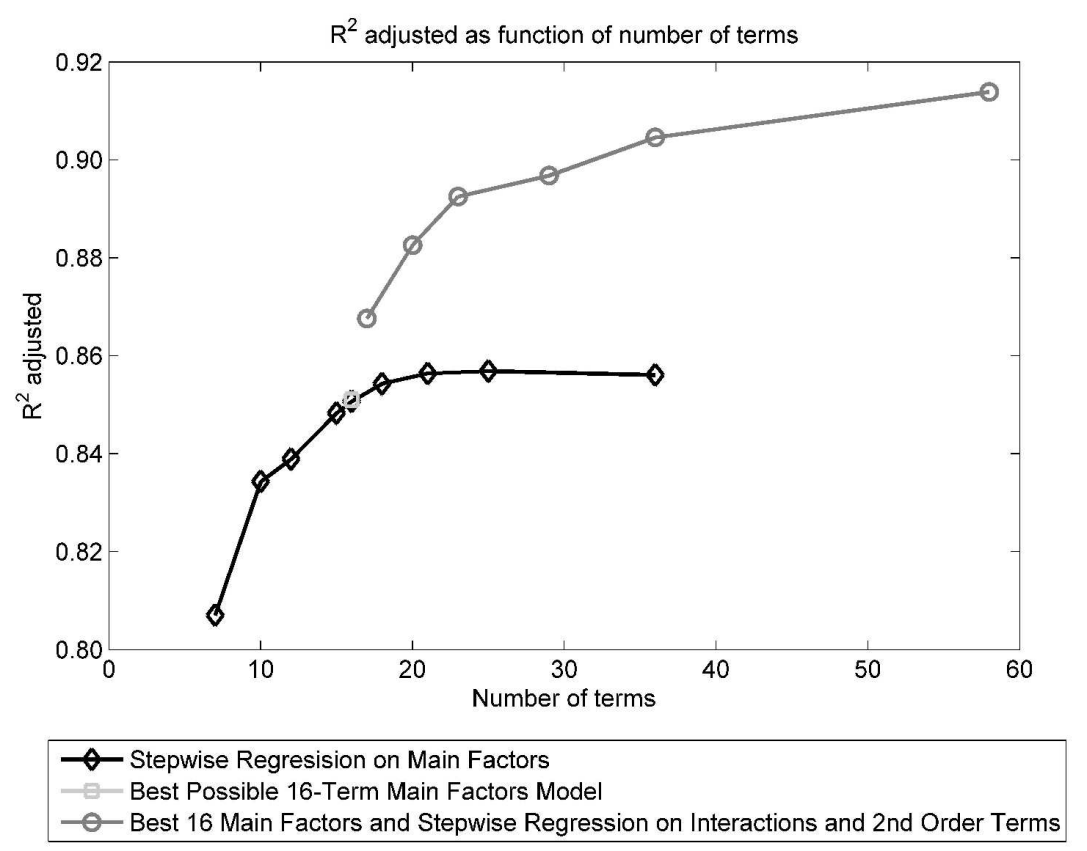

Figure 22. Addition of interactions and $2^{\text {nd }}$ order terms in the statistical model. 
The results show that including interactions can significantly improve the model fit. Based on the above diagram, a model with 23 terms was chosen as it gives good compromise between complexity and the quality of fit. For comparison a 20 term model is also included in Table 9.

\begin{tabular}{|c|c|c|c|c|}
\hline TSTAT: & \multicolumn{2}{|c|}{5} & \multicolumn{2}{|c|}{6} \\
\hline Metric & TSTAT & coefficient & TSTAT & coefficient \\
\hline${ }^{F} \gamma_{V}$ & 12.08284 & 4524.174 & 12.27968 & 4779.185 \\
\hline${ }^{F} K_{V 1 r}$ & -4.13178 & -0.84496 & 13.98935 & 0.250867 \\
\hline${ }^{F} K_{V 1 b}$ & 1.427189 & 0.072421 & -0.02648 & -0.00137 \\
\hline${ }^{F} K_{V 2 b}$ & -8.93141 & -0.07417 & -8.08901 & -0.07003 \\
\hline${ }^{F} \alpha_{V^{2}}$ & -4.50119 & -32422.9 & -4.42448 & -33270.6 \\
\hline${ }^{F} \psi_{V}$ & 7.947827 & 83.03506 & 7.452588 & 81.34546 \\
\hline${ }^{R} \gamma_{V}$ & -1.00784 & -334.532 & -7.41488 & -1769.59 \\
\hline${ }^{R} K_{V 1 b}$ & -9.78957 & -0.30481 & -22.3506 & -0.14861 \\
\hline${ }^{R} \alpha_{V}$ & 7.713683 & 121.3813 & 7.368396 & 120.9666 \\
\hline${ }^{R} \psi_{V}$ & -9.86778 & -397.396 & -9.81768 & -412.568 \\
\hline${ }^{R} \rho_{V}$ & -8.65296 & -0.4563 & -8.80496 & -0.48388 \\
\hline${ }^{F} \gamma_{L}$ & -6.99715 & -154181 & -30.1908 & -260712 \\
\hline${ }^{F} \psi_{L}$ & 5.517819 & 34239.66 & 4.980048 & 32216.93 \\
\hline${ }^{R} \gamma_{L}$ & 0.055234 & 2613.999 & -17.5857 & -242492 \\
\hline${ }^{R} \varphi_{L}$ & 8.014139 & 280.8634 & 8.132765 & 297.3028 \\
\hline${ }^{F} K_{R}$ & -27.8578 & -0.05478 & -26.2715 & -0.05389 \\
\hline${ }^{F} \gamma_{V} \cdot{ }^{F} K_{V 1 b}$ & -10.621 & -14.2986 & -10.4611 & -14.7018 \\
\hline
\end{tabular}


Table 9. Summary of models including interactions and $2^{\text {nd }}$ order terms.

For convenience it is worth stating here the full meaning of the significant interactions in the 23 term model:

- front linear camber gain and front suspension rate in bump on centre

- front linear camber gain and rear roll centre height

- front suspension rate in rebound on centre and rear linear camber compliance

- front suspension rate in bump on centre and rear linear camber compliance

- front suspension rate in full bump and front suspension roll stiffness

- rear suspension rate in bump on centre and front linear camber compliance

- additionally rear suspension linear camber gain squared is also significant.

One may notice that introduction of interactions has pushed the t-statistics of some of the main factors below the originally specified value of 5 used to derive the 23 term model. The factors affected the most are:

- rear linear camber gain 
- rear linear camber compliance

However, as interactions include these factors, they are left in the model despite having low t-statistics values. In order to better understand the strength of each of the main factors, a conversion table has been constructed (Table 10).

\begin{tabular}{|c|c|c|c|c|}
\hline & Desired change to increase $V_{\text {Critical }}$ & Change of & Unit & Effect on $V_{\text {Critica }}$ \\
\hline${ }^{F} \gamma_{V}$ & less negative camber gain with bump & 0.002 & $\mathrm{deg} / \mathrm{mm}$ & 9.048 \\
\hline${ }^{F} K_{V 1 r}$ & softer & -10 & $\mathrm{~N} / \mathrm{mm}$ & 8.450 \\
\hline${ }^{F} K_{V 1 b}$ & stiffer & 10 & $\mathrm{~N} / \mathrm{mm}$ & 0.724 \\
\hline${ }^{F} K_{V 2 b}$ & softer & -10 & $\mathrm{~N} / \mathrm{mm}$ & 0.742 \\
\hline${ }^{F} \alpha_{V^{2}}$ & more toe out change with bump and rebound & -0.00002 & $\operatorname{deg} / \mathrm{mm}^{2}$ & 0.648 \\
\hline${ }^{F} \psi_{V}$ & less WC track change & 0.01 & $\mathrm{~mm} / \mathrm{mm}$ & 0.830 \\
\hline${ }^{R} \gamma_{V}$ & more negative camber in bump & -0.002 & $\mathrm{deg} / \mathrm{mm}$ & 0.669 \\
\hline${ }^{R} K_{V 1 b}$ & softer & -10 & $\mathrm{~N} / \mathrm{mm}$ & 3.048 \\
\hline${ }^{R} \alpha_{V}$ & more toe in with bump & 0.005 & $\operatorname{deg} / \mathrm{mm}$ & 0.607 \\
\hline${ }^{R} \psi_{V}$ & more $\mathrm{WC}$ track change & -0.01 & $\mathrm{~mm} / \mathrm{mm}$ & 3.974 \\
\hline${ }^{R} \rho_{V}$ & lower roll centre & -10 & $\mathrm{~mm}$ & 4.563 \\
\hline${ }^{F} \gamma_{L}$ & higher camber compliance & -0.00001 & $\operatorname{deg} / \mathrm{N}$ & 1.542 \\
\hline${ }^{F} \psi_{L}$ & lower WC compliance & 0.00002 & $\mathrm{~mm} / \mathrm{N}$ & 0.685 \\
\hline${ }^{R} \gamma_{L}$ & lower camber compliance & 0.00001 & $\operatorname{deg} / \mathrm{N}$ & 0.026 \\
\hline${ }^{R} \varphi_{L}$ & less jacking force & 0.02 & $\mathrm{~N} / \mathrm{N}$ & 5.617 \\
\hline${ }^{F} K_{R}$ & softer in roll & -150 & $\mathrm{~N} / \mathrm{deg}$ & 8.217 \\
\hline
\end{tabular}

Table 10. Summary most influential K\&C metrics on rollover propensity. 
1

2

3

4

5

8

10

11

12

13

14

15

16

17

18

19

20

21

22

23

24

25

26

27

28

29

30

31

32

33

34

35

36

37

38

39

40

41

42

43

44

45

46

47

48

49

50

51

52

53

54

55

56

For comparison, on average, $1 \mathrm{~mm}$ change in the vehicle sprung mass $\mathrm{CoG}$ results in $1.24 \mathrm{~m} / \mathrm{s}$ change in critical rollover velocity, as seen on Figure 23.

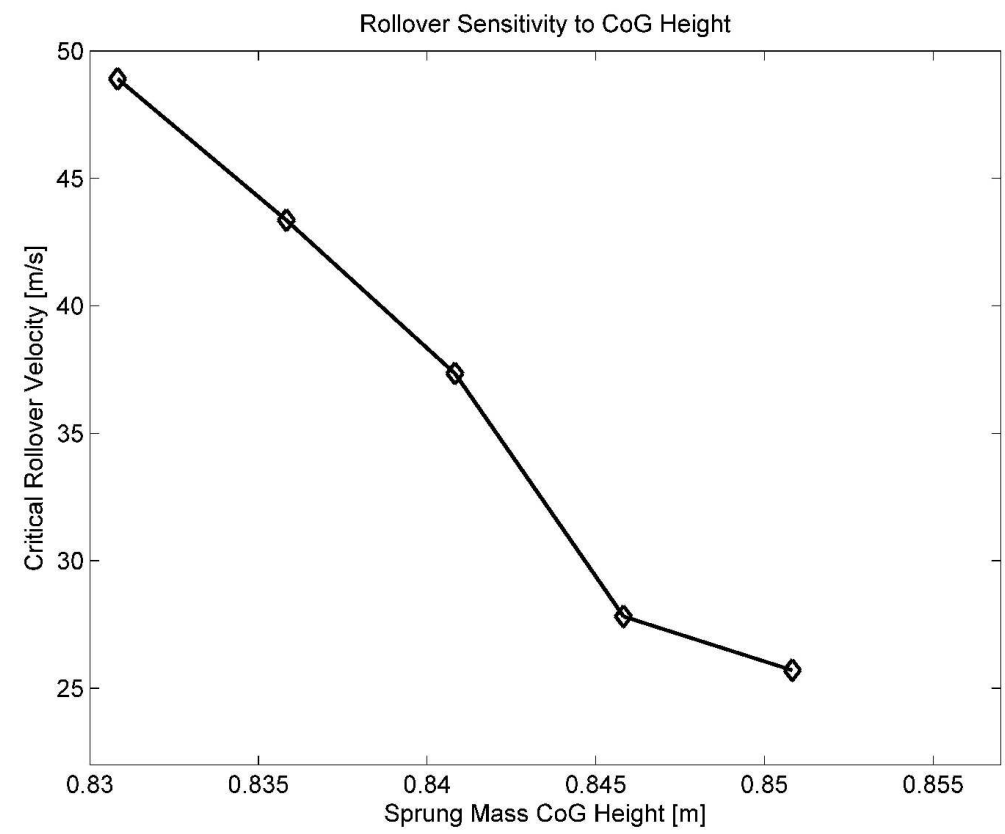

Figure 23. Rollover sensitivity to sprung mass CoG.

\section{Conclusions}

A high-fidelity multi-DOF vehicle model of an SUV was used to carry out an investigation into the influence of tyre parameters and $\mathrm{K} \& \mathrm{C}$ characteristics on rollover propensity. In contrast to a purely qualitative approach in analysing the results, a DoE method and statistical tools were used in order to capture the dependency of rollover on some of the principal tyre and $\mathrm{K} \& \mathrm{C}$ parameters. In terms of sensitivity to tyre parameters, road-tyre friction manifested as the major parameter that promotes or prevents rollover. This parameter, however, depends on the quality of the road surface as well, so does not seem to be easily controllable. On the other hand, tyre camber stiffness seems to also play an important role in rollover propensity. Camber stiffness is a parameter closely related to the construction of the tyre and thus can be tuned in order 
to prevent rollover.

In terms of sensitivity to $\mathrm{K} \& \mathrm{C}$ characteristics, key metrics and their interactions were found from a set of 36 metrics. The results indicate that the most influential suspension characteristics are front and rear suspension rate, front roll stiffness, front camber gain, front and rear camber compliance, rear jacking force. This knowledge and the associated methodology should be useful in the vehicle development process as it enables engineers to estimate the effects that changes made to suspension design will have on vehicle rollover propensity. 
References:

[1] National Highway Traffic Society Administration, Traffic Safety Facts 2005: A Compilation of Motor Vehicle Crash Data from the Fatality Analysis Reporting System and the General Estimates System, Technical Report, 2007

[2] Altman, S., Santistevan, D., Hitchings, C., 2002, A Comparison of Rollover Characteristics for Passenger Cars, Light Duty Trucks and Sport Utility Vehicles, SAE Technical Paper 2002-01-0942

[3] Marimuthu, R., P., Jang, B. -C., Hong, S., J., A Study on SUV Parameters Sensitivity on Rollover Propensity, SAE paper, 2006

[4] Jin, Z., L., Weng, J., S., Hu, H., Y., Rollover stability of a vehicle during critical driving manouvres, Proc. IMechE Vol. 221 Part D: Journal of Automobile Engineering, 2007

[5] Hamblin, B., C., Martini, R., D., Cameron, J., T., Brennan, S., N., Low-Order Modeling of Vehicle Roll Dynamics, Proceedings of the 2006 American Control Conference, IEEE paper, 2006,

[6] Gertsch, J., Shim, T., Insightful Representations of Roll Plane Model Stability Limits, SAE Technical Paper 2006-01-1284, 2006

[7] Lozia, Z., Rollover thresholds of the biaxial truck during motion on an even road, Vehicle System Dynamics, 29:1, 735-740, 1998

[8] Shim, Taehyun and Ghike, Chinar, Understanding the limitations of different vehicle models for roll dynamic studies, Vehicle System Dynamics, 45:3, 191-216, 2007

[9] Ghike, Ch., Shim, T., 14 Degree-of-Freedom Vehicle Model for Roll Dynamics Study, SAE Technical Paper 2006-01-1277, 2006

[10] Hac, A., Influence of Chassis Characteristics on Sustained Roll, Heave and Yaw Oscillations in Dynamic Rollover Testing, SAE Technical Paper 2005-01-0398, 2005

[11] Hac, A., Influence of Active Chassis Systems on Vehicle Propensity to Maneuver-Induced Rollover, SAE Technical Paper 2002-01-0967, 2002

[12] Cole, D. J., Fundamental Issues in Suspension Design for Heavy Road Vehicles, Vehicle System Dynamics, 35:4, 319-360, 2001 
[13] Hussain, K., Stein, W., Day, A.J., Modeling commercial vehicle handling and rolling stability, Proc. IMechE Vol. 219, Part K: Journal of Multi-body Dynamics, 2005

[14] Rahnejat, H. Multi-body dynamics: vehicles, machines, and mechanisms, Professional Engineering, London, 1998.

[15] Murray, R., M., Li, Z., Sastry, S., S., A Mathematical Introduction to Robotic Manipulation, CRC Press, 1994.

[16] Wallrapp, O., Review of Past Developments in Multibody System Dynamics at DLR - From FADYNA to SIMPACK, Vehicle System Dynamics, 41:5, 339-348, 2004

[17] Hippmann, G., Introduction to SIMPACK's MBS-Formalism, 2010-09-14, presented at SIMPACK Academy

[18] MF-Tyre/MF-Swift 6.1.2 Help Manual, 2010

[19] Montgomery, D., C., Design and Analysis of Experiments, Fifth Edition, John Wiley \& Sons, Inc. , 2001

[20] Antony, Jiju, Design of Experiments for Engineers and Scientists, First Edition, Elsevier Publishing, 2004

[21] Gillespie, T., Fundamentals of Vehicle Dynamics, 1992, SAE PA 15096-0001

[22] Eger, R., Kiencke, U., 2003, Modeling of rollover sequences, Control Engineering Practice, 11, 209-216

[23] Teknikens Värld nummer 23/1997

[24] Garrick J. Forkenbrock, W. Riley Garrot, Matk Heitz, Bryan C. O'Harra, $A$ Comprehensive Experimental Evaluation of Test Maneuvers That May Induce On-Road, Untripped, Light Vehicel Rollover. Phase IV of NHTSA's Light Vehicle Rollover Research Program, 2002, NHTSA Report No DOT HS 809 513

[25] Dutton, K., Thompson, S., Barraclough, B. The Art of Control Engineering, Addison Wesley, 1997

[26] Cook, P.A. Nonlinear Dynamical Systems, Prentice Hall, 1994 


\section{Appendix A: List of abbreviations}

CoG - Centre of Gravity

DoE - Design of Experiment

DoF - Degree of Freedom

DSF - Dynamic Stability Factor

$\mathrm{K} \& \mathrm{C}$ - Kinematics and Compliance

MBS - Multi-Body Simulation

MF - Magic Formula

ODE - Ordinary Differential Equation

PPT - Phase Plane Trajectory

PID - Proportional Integral Differential

SUV - Sport Utility Vehicle 